\title{
PAROXYSMAL VENTRICULAR TACHYCARDIA
}

\author{
BY \\ W. TREVOR COOKE * AND PAUL D. WHITE \\ From the Cardiac Laboratory, Massachusetts General Hospital, Boston, Mass., U.S.A. \\ Received May 14, 1942
}

Paroxysmal ventricular tachycardia is comparatively rare. It was first differentiated from paroxysmal auricular tachycardia by MacKenzie (1908) through his study of simultaneous venous and arterial tracings. Others (Franck, 1894, and Hoffman, 1900) had hinted that this might be the case. The following year Lewis (1909) published the first electrocardiogram that supported this contention; the rhythm consisted of numerous isolated or continuous extrasystoles, eleven being the most occurring in one run.

Since Lewis's pioneer studies $(1909,1910)$, many workers have brought about a clearer conception of the condition and its prognostic significance. Their articles will be considered in more detail elsewhere in this paper.

\section{DiAgnOSIS}

Clinical evidence. Levine and Strong (1923) pointed out that it may be possible to make a diagnosis of ventricular tachycardia at the bedside. In auricular tachycardia the rhythm on auscultation appears to be absolutely regular. In ventricular tachycardia, however, there is sometimes an arrhythmia and sometimes a variation in the intensity of the first heart sound. Whether, howeve:, it is possible to differentiate with any certainty this condition when showing arrhythmia from paroxysmal flutter with varying block or even from fibrillation at the rate of about 140, is extremely doubtful. Gallavardin (1920) and Prinzmetal and Kellog (1934) again drew attention to MacKenzie's observation that the presence of ventricular tachycardia can be shown by observation of the jugular pulse ; regularly recurring auricular waves at a slower rate than the pulse rate may be noted in some cases.

There is one further point that could be of some assistance in the diagnosis: the occurrence of a sudden marked rise and fall in the pulse rate in a patient with long-standing auricular fibrillation means that the episode is probably due to paroxysmal ventricular tachycardia, especially after heavy digitalization. Any of these points might suggest the diagnosis but the final and only proof is the electrocardiogram.

Electrocardiographic records. Robinson and Herrman (1921) were the first to lay down the diagnostic criteria-" The electrocardiogram must show that the cardiac impulses are arising in the ventricles and this is most clearly shown when a succession of auricular complexes can be made out occurring independently of and at a slower rate than the complexes of ventricular origin. The ventricular complexes are distinctly abnormal in form. This alone, however, cannot be taken as absolute proof as changes in form may be caused by changes in intraventricular conduction. When records made between attacks show there is no such disturbance then, the ventricular origin of the tachycardia is very probable, although disturbances of conduction may appear at a high cardiac rate which are not apparent when the heart is beating slowly. The presence of isolated ectopic beats before or after a paroxysm is evidence in favour of the tachycardia being ventricular, especially when the form of the complexes of the isolated beats is the same as the form of those of the paroxysm."

The presence of ectopic beats, however, before or after a paroxysm has no diagnostic significance, though Campbell and Elliott (1939) believe that where supraventricular extrasystoles are observed, the paroxysms are always of auricular origin. Amongst the cases to be described here, there are some with auricular premature beats occurring before and after the paroxysms of ventricular origin (Fig. 1). Isolated complexes identical with those of the paroxysm are almost impossible to find: the criteria should be changed so that the complex of an ectopic ventricular beat which is almost the same as those of a tachycardia may denote the ventricular origin of the paroxysm (Fig. 2 and 18).

* This work was done while holding a Research Fellowship in Medicine, Harvard University, 1938-39, and Walter Myers Travelling Studentship, Birmingham University, 1938-39. The basis of this paper formed part of a thesis submitted by one of us (W. T. C.) and accepted for the degree of M.D. of the University of Cambridge. 

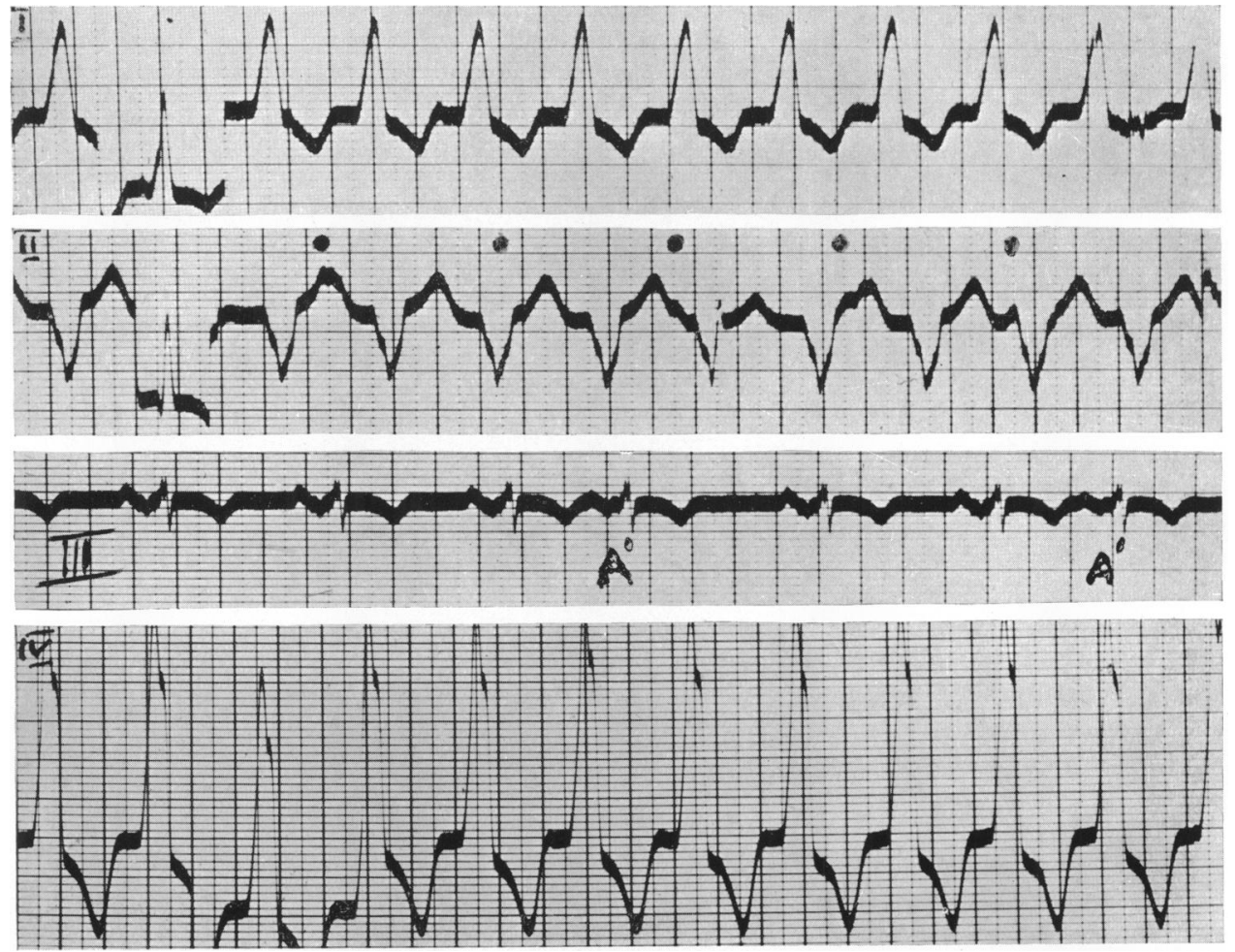

FIG. 1.-Case 22. Ventricular paroxysmal tachycardia, rate 140; auricular rate 75. Breaks in the ventricular rhythm in leads I and II are shown. The single beat in lead I simulates the Wolff-Parkinson-White type. Two premature auricular beats are shown during normal rhythm in lead III (marked A). The dots indicate the site of $P$ waves.
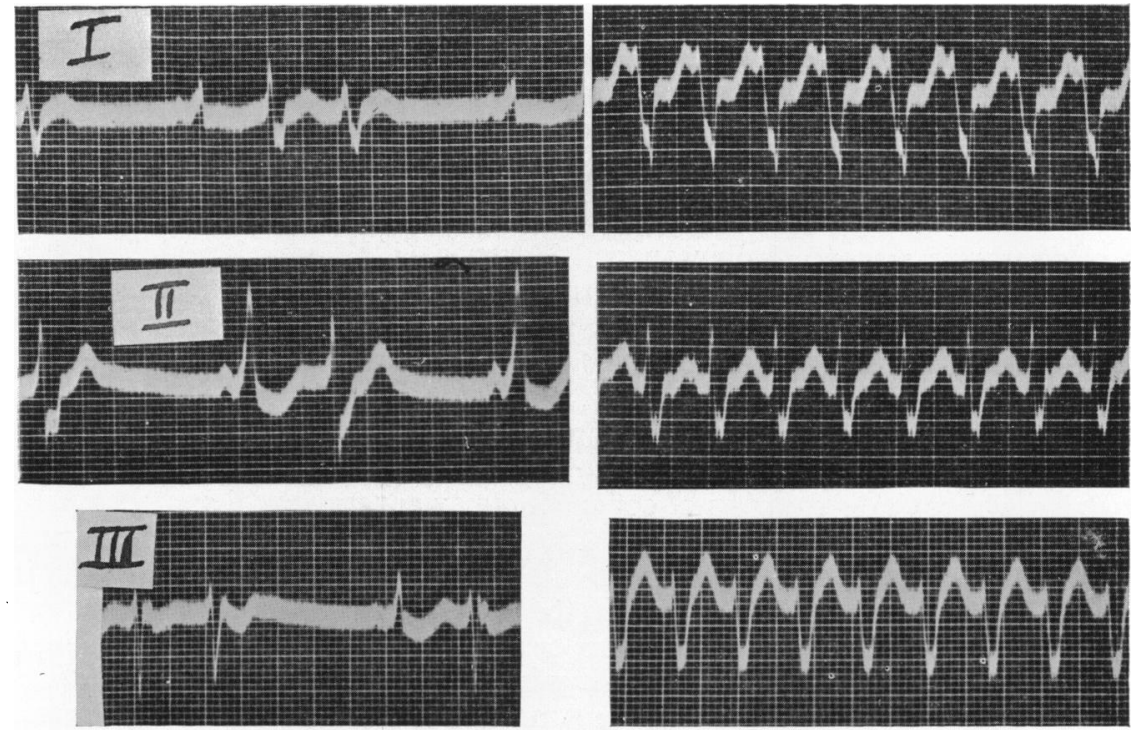

Fig. 2.-Case 27. Wolff-Parkinson-White type. On the left, S-A rhythm with numerous ventricular extrasystoles. On the right, paroxysmal ventricular tachycardia. No $P$ waves can be identified but the ventricular complexes are sufficiently similar to the extrasystoles during normal rhythm to make the diagnosis.

Further, as has been suggested above, a succession of abnormal ventricular complexes occurring regularly and at a rate faster than the usual ventricular rate in the course of auricular fibrillation denotes ventricular tachycardia. 
Lewis (1925) pointed out that it is difficult to be certain of the origin of paroxysmal tachycardia in any given example unless $\mathbf{P}$ waves or the beginning or end of the paroxysm are recorded. The actual mode of ending is not always a reliable index, as the compensatory pauses and the normal rhythm after both auricular and ventricular tachycardias is subject to great variation. However, on a few occasions the $\mathrm{T}$ wave of the last complex of a paroxysm is not the same as the remainder, thus providing evidence of superimposed and hidden $P$ waves on the remaining $T$ waves and so of its auricular origin. But in many examples of known auricular tachycardia this may be difficult to detect.

Strong and Levine (1923) carefully measured the time intervals between the QRS complexes and pointed out that there was much variation as opposed to the comparative regularity of auricular paroxysmal tachycardia. This has been used by some in differentiating the doubtful cases. We have, however, encountered cases of very regular rhythm in ventricular, and of considerable arrhythmia in auricular tachycardia. Too much stress has been laid on the irregularity.

Radiology. Kahlstorf (1936) states that with the kymograph it is possible to present indisputable evidence. He recorded one case of paroxysmal auricular tachycardia in which he was able to demonstrate the auricular rate of 280 satisfactorily by this method. He suggested that the method should be tried in ventricular tachycardia, and it might perhaps be useful where the diagnosis is doubtful.

Differential diagnosis. Some of the difficulties in diagnosis have already been mentioned. They can be well illustrated by Fig. 3, which was originally interpreted as showing ventricular tachycardia. It is, however, impossible to make out any auricular activity and the shape of the ventricular complexes may be due to aberration, so that one would not be justified in a definite diagnosis. The influence of the rate can well be shown in Fig. 4. The first record shows auricular flutter (A, 270; V, 135), while the second, taken in another attack with the same auricular rate, showed a $1: 1$ response of the ventricles but with aberration of the ventricular complexes.

Cases of the type described by Wolff, Parkinson, and White with a short P-R interval and wide QRS complexes cause some difficulty in diagnosis. They frequently maintain their abnormal complexes during a paroxysm or they may develop a greater degree of aberration or indeed actual ventricular tachycardia which is, however, rare (Fig. 2). Only a few other cases of ventricular tachycardia complicating this syndrome have been reported (Levine and Beeson, 1941). One of us (P. D. W.) believes that another case (Fig. 5) also shows paroxysmal ventricular tachycardia but it is not possible to identify any regular $\mathbf{P}$ waves or satisfy the other criteria laid down, so that paroxysmal auricular fibrillation cannot be ruled out as a possible diagnosis. Such rhythms in this type have caused difficulties in diagnosis on many occasions (Fig. 6).

These difficulties in diagnosis amply illustrate the necessity of applying strict criteria to the interpretation of the electrocardiograms in these cases.

Criteria for diagnosis. In the cases that are reported here, the following four electrocardiographic criteria have been applied.

1. The presence of $P$ waves at a slower rate than that of the ventricles, during a paroxysm of tachycardia (Fig. 1).

2. A paroxysm of abnormal ventricular complexes, i.e. three or more at a rapid rate, occurring during auricular fibrillation (Fig. 7).

3. The onset of the tachycardia with an abnormal ventricular complex (Fig. 8).

4. Close resemblance of the complexes of ventricular premature beats to the complexes occurring during paroxysmal tachycardia (Fig. 2 and 18).

Any one of these conditions establishes the diagnosis of paroxysmal ventricular tachycardia.

\section{Present Study}

Number of cases. All cases of ventricular paroxysmal tachycardia occurring in the cardiographic records of the Massachusetts General Hospital during the 25 years from 1914 to 1939 have been collected. These were 24 cases among 51,000 records from about 25,000 patients. There were in addition, 3 patients whose tracings had been taken elsewhere. Three patients have previously been reported (Case 24, Jones \& White, 1926; and Cases $1 \&$ 9, Palmer \& White, 1928). In addition to these 27 cases, there have been included in the appendix 5 further cases that had been diagnosed previously as ventricular but should be classed as doubtful or auricular in origin.

AEtiology. Of the 27 cases, 22 had coronary heart disease; 4 of these were still living when this study was completed in 1939; and 1 had not been traced. The remaining 5 had no other cardiac abnormality; 4 were alive and 1 had not been traced. 

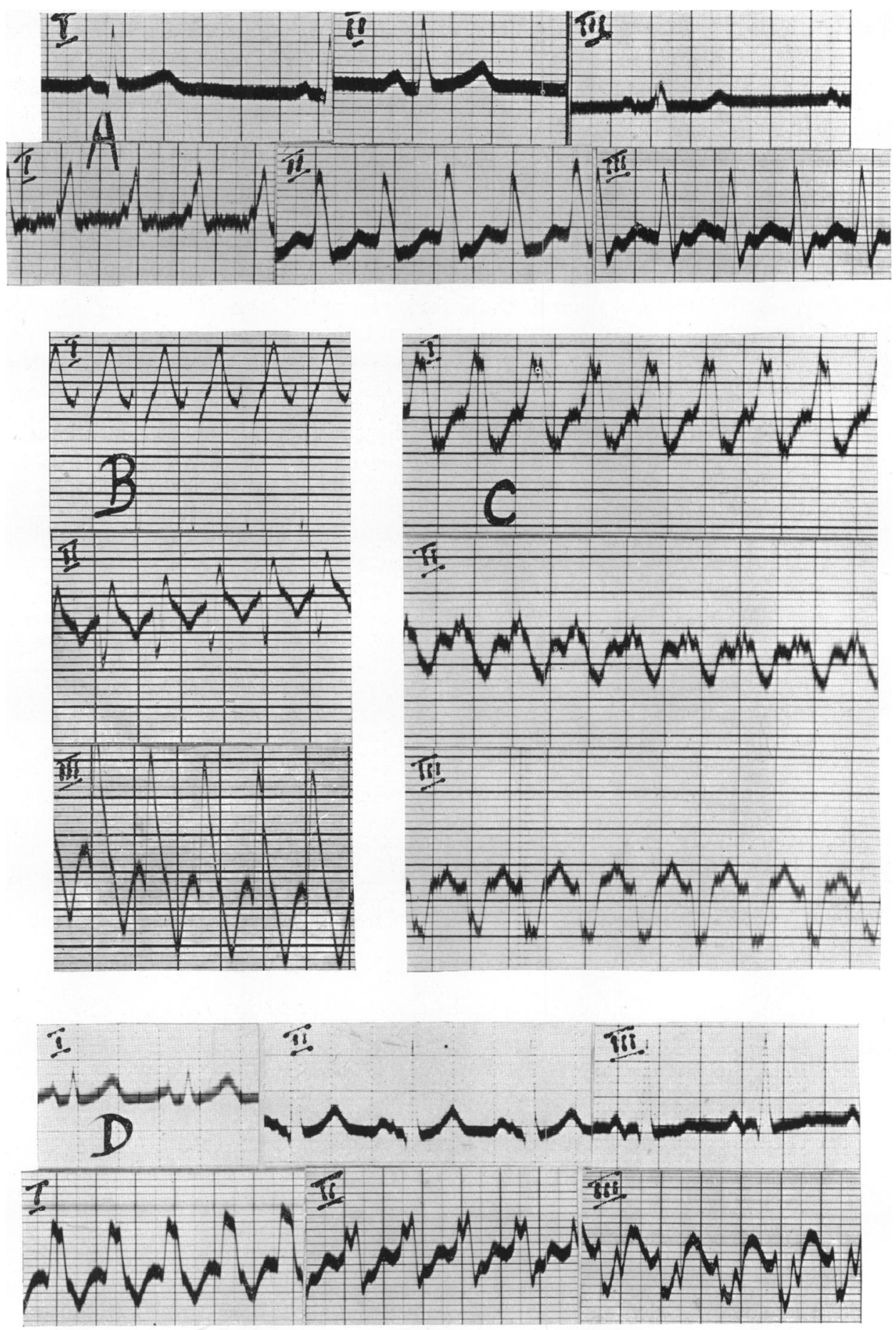

FIG. 3.- Short tracings from four patients (see appendix) in which there was insufficient evidence to make a diagnosis of paroxysmal ventricular tachycardia.

(A) and (B) are probably auricular in origin with aberrant conduction in the ventricles due to the rate, while (C) and (D) are possibly ventricular. No definite $P$ waves can be made out in any of the records.

(A) Case 28. (B) Case 29. (C) Case 30. (D) Case 32. 


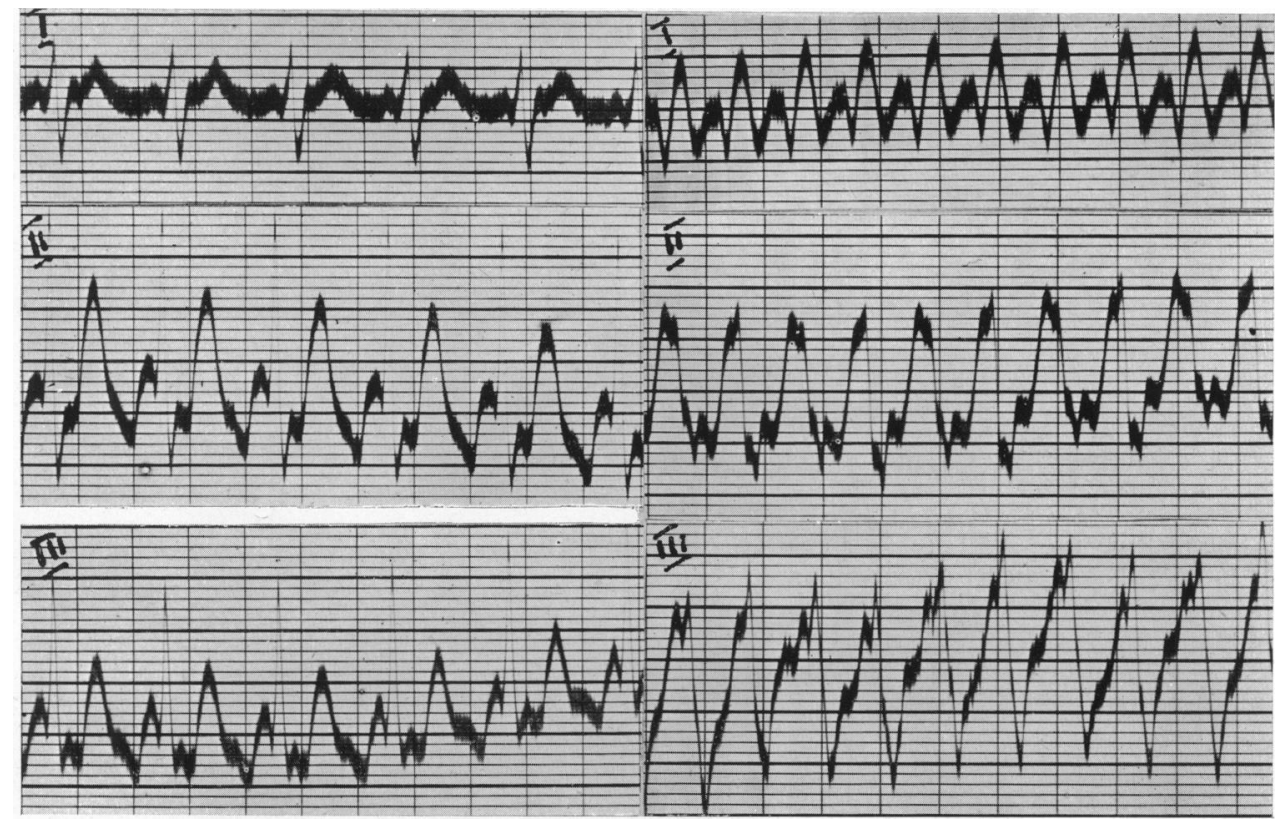

A

B

FIG. 4.-Electrocardiograms, one of which simulates ventricular paroxysmal tachycardia. Both are from the same patient, and the auricular rate in each is 270 , but $2: 1$ block is present in (A) and in (B) there is an aberrant ventricular response to every auricular beat.

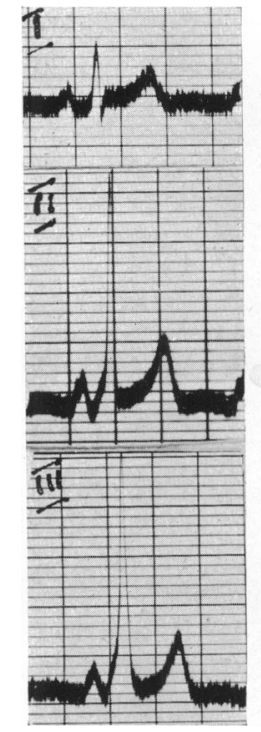

A

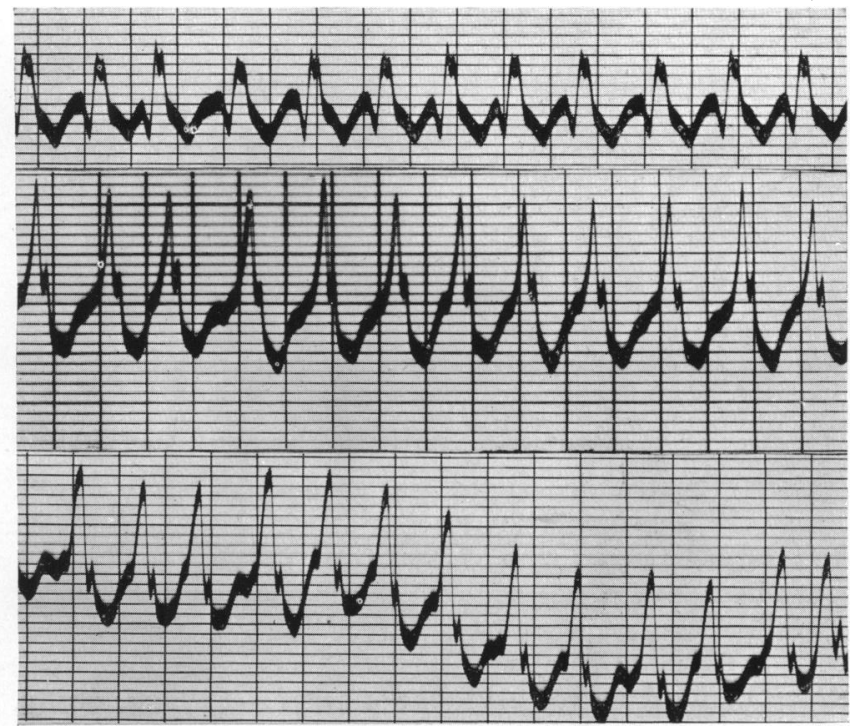

B

FIG. 5.-Case 31. On the left (A), normal rhythm with a short P-R interval and wide QRS complex (WolffParkinson-White type). On the right (B), either paroxysmal ventricular tachycardia or paroxysmal auricular fibrillation. Possible $P$ waves can be made out but no regular rhythm can be shown. The diagnosis must remain doubtful. 


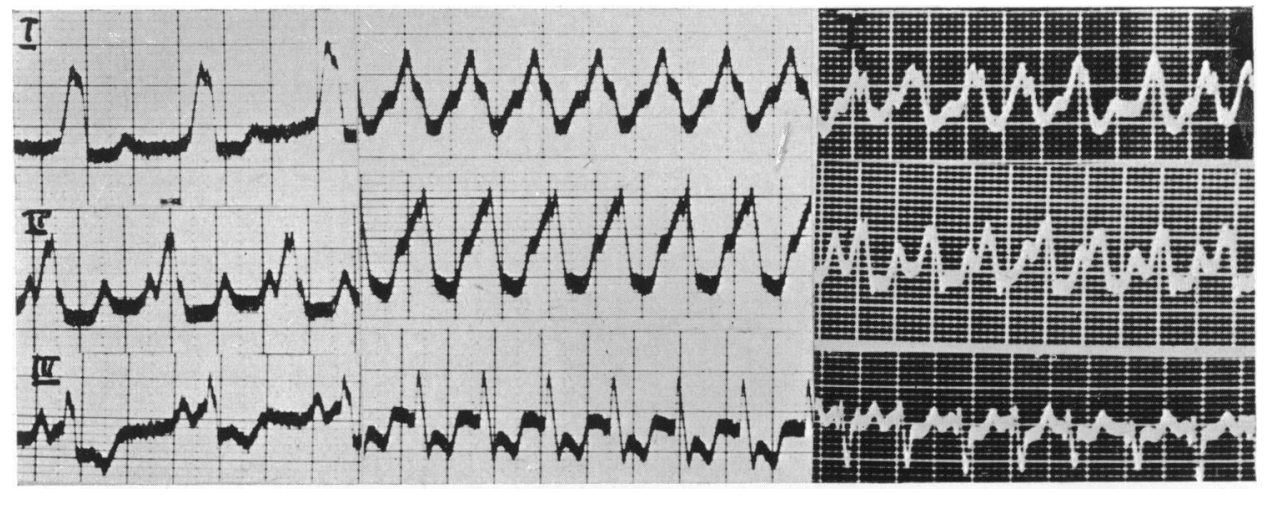

A

B

C

FIG. 6.-Wolff-Parkinson-White type. (A) Normal rhythm, (B) paroxysmal auricular tachycardia (or flutter), and (C) paroxysmal auricular fibrillation. All three records from the same patient, illustrating similarities in appearance to ventricular tachycardia.

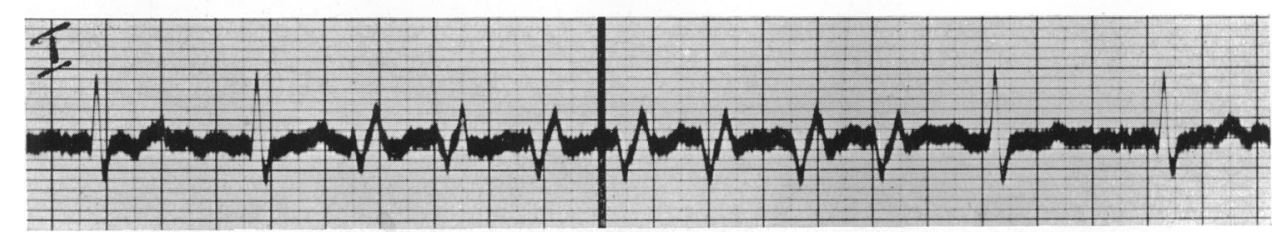

FIG. 7.-Case 17. Short paroxysm of ventricular tachycardia occurring during auricular fibrillation.

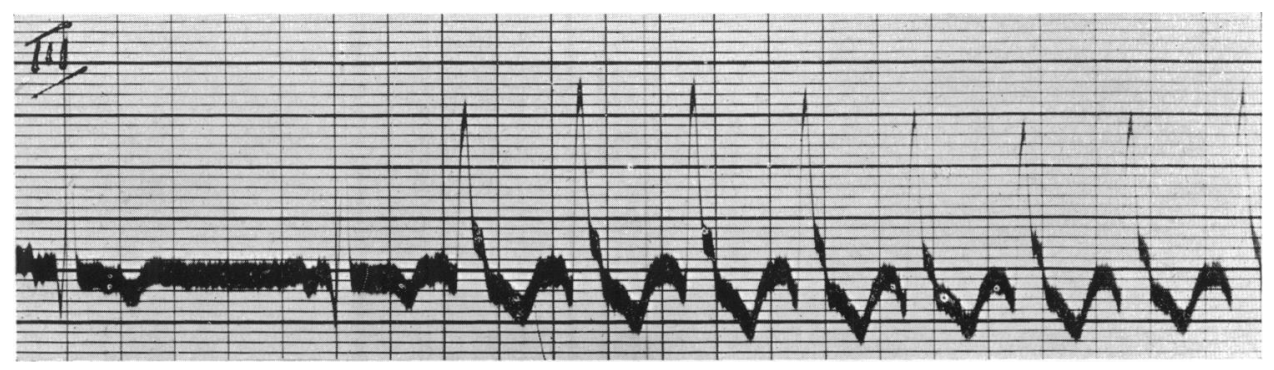

FIG. 8.-Case 24. Onset of a paroxysm shortly after the end of a $T$ wave.

Sex incidence. 17 were males and 10 females. This ratio is somewhat higher for females than the figures that were given by Lundy and McLellan (1934) who found in their analysis of 94 reported cases that there were 68 males and 26 females: 14 of these 94 cases had no other cardiac abnormality.

Age incidence. The age incidence of our group is shown in Fig. 9. The table given by Strauss (1930) has been used for comparison (the lower part of the columns) and the figures of our group have been added (in the upper part of the columns). As would be expected, the greatest incidence accompanies the decade with the greatest incidence of coronary heart disease.

The youngest patients recorded have been aged 13 (Beeson \& Levine, 1941), and 16 (McMillan \& Bellet, 1932, and Lundy \& McClellan, 1934). Our youngest patient (Case 24) was aged 18), but his father, a physician, had observed the attacks since the age of five.

\section{The Role Played by Digitalis}

Traube (1851) pointed out that large doses of digitalis at first slow the heart and later increase the rate to one far exceeding that of the normal heart. This he supposed was due to the paralysis of the vagus.

Francois-Franck (1894), as a result of his experiments, described in remarkable detail the various disturbances of rhythm that took place. The digitalis arrhythmia was characterized by: repeated 


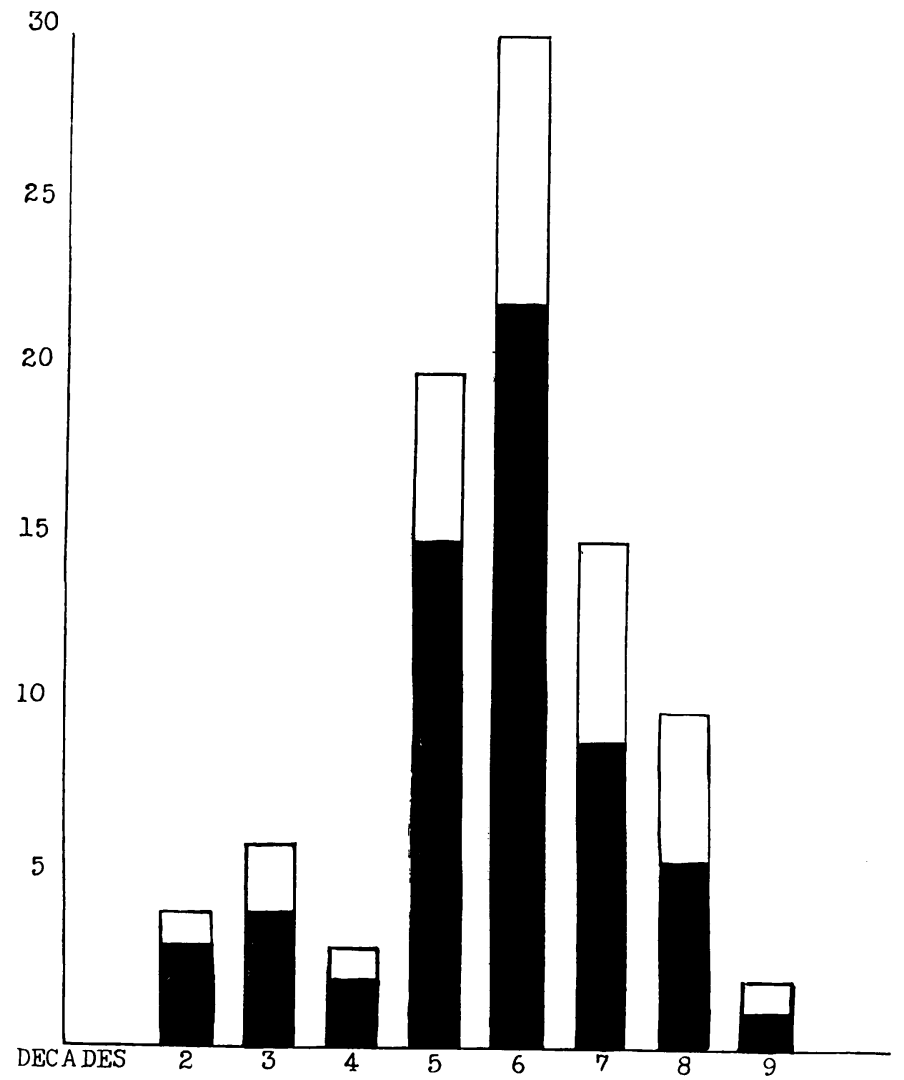

FIG. 9.-The age incidence of paroxysmal ventricular tachycardia. The figures for this series have been placed above those given by Strauss (1930), making a total of 90 cases in all.

close beats in groups of two, three, or more, producing the bigeminal or trigeminal pulse; numerous extrasystoles that are scarcely perceived at the wrist; groups of semi-tetanic contractions; intermittence of the heart for varying periods; and regular beats, with or without extrasystoles, between two periods of tachycardia. He completed his description-" Tous les désaccordes sont possible sous l'influence de la digitaline entre la fréquence et le rythme auriculaires et la fréquance et le rythme ventriculaires: les modifications des ventricules ne sauraient dône être subordonnées à celles de l'oreillette."

Cushny (1897), in his very extensive researches, noted exactly the same phenomena and believed that they were due to the increasing irritability of the cardiac muscle. All these findings were later confirmed by Robinson and Wilson with the aid of the electrocardiograph (1918).

Turning from experimental to clinical evidence, Vaughan (1918) suggested that the tachycardia observed in his two cases might be due to digitalis. Schwensen (1922) reported two cases and wrote that probably the administration of digitalis directly caused the attacks of ventricular tachycardia. He suggested that the sudden and unexpected deaths of patients under digitalis therapy was due to ventricular fibrillation resulting from overdosage.

Danielopolu in the same year (1922) published a report of three cases which he had observed in 1911 and 1913 and also ascribed them to digitalis or strophanthus. From the records published (pulse tracings) it is difficult to be sure of the exact nature of the tachycardia.

During the next few years there were numerous reports which illustrated the potentialities of digitalis in producing this rhythm (Fellerbaum, 1923; Reid, 1924; Marvin, 1928; etc.). Luten $(1924,1925)$ showed quite convincingly in a series of articles, the similarity between over-digitalization in animals, as demonstrated by Robinson and Wilson, and in patients. He regarded the alternation of the ventricular complexes which was being noted fairly frequently in such cases as the stage of intoxication just prior to fibrillation, and as an effect upon the conduction system rather than upon the muscle.

Gilchrist in 1926 recorded 5 cases of ventricular paroxysmal tachycardia and showed conclusively in one case that the abnormal rhythm appeared only upon the administration of digatalis and disappeared when the drug was withdrawn. Strauss (1930) found that of the 64 cases recorded 
to that time, digitalis had been administered before the onset of the tachycardia in about 50 per cent, and of these there were some excessive doses while in others the dose was probably too small to have any effect. However, as Gilchrist had pointed out, and as Scherf and Kisch pointed out later, in very damaged and abnormal hearts even small doses of digitalis may be sufficient to cause abnormalities of rhythm.

An excellent commentary and summary of the effects of digitalis is given by Scherf and Kisch (1939), who reported the results of their observations, extending over fourteen years, upon 18 patients with ventricular paroxysmal tachycardia and alternating complexes. In 14, digitalis was probably the provoking and determining factor, but in 4 no digitalis was given; in these latter cases, they believed that there was gross myocardial damage. They thought that digitalis cannot produce the arrhythmia unless the heart is already damaged, because Kobacher and Scherf (1930) were unable to produce such arrhythmias in normal hearts of animals, and also because the reports of cases of suicide contain no mention of the production of any arrhythmia (e.g. Albeaux, Fernet, \& Welti, 1939). In some of their cases the tachycardia frequently disappeared if the digitalis was discontinued but it returned if the drug was given again. On the other hand, tachycardia may not develop after the administration of excessive amounts of digitalis over a long period. They, therefore, assumed that the quantity of digitalis administered is not the factor of exclusive importance, but that the state of the heart muscle is chiefly responsible. They recorded one case in which the rhythm disappeared only during the administration of large doses of quinidine and of digitalis, in a young man aged 23 years.

There were 12 out of our 27 cases to which no digitalis had been given before the onset of the tachycardia. Of these, 5 were cases in which the only apparent abnormality was the arrhythmia, i.e. with presumably normal hearts. Of the 15 cases to which digitalis had been given, there were 5 in which the dosage had been greater than normal, and we are warranted in assuming that digitalis played a large part in the production of the paroxysm (Cases $2,5,6,13, \& 18$; see appendix). There were 10 other cases to which digitalis had been given prior to the tachycardia (Cases 1, 3, 4, $8,9,10,11,16,17, \& 19)$.

Of the 7 cases of coronary heart disease that had had no digitalis before the onset of the tachycardia, there were 4 to which digitalis was administered in average doses after the onset (Cases 14, 20,21, \& 22).

There remain 5 cases of apparently normal hearts with ventricular paroxysmal tachycardia. These all had digitalis given to them at one time or another, in various dosage, without any noticeable effect, either in increasing the frequency or diminishing the number of the attacks.

To summarize, out of 22 cases of coronary heart disease showing ventricular paroxysmal tachycardia, 5 were probably related to digitalis administered, and 3 others may possibly have been so related; 1 in which no digitalis had been given before, may have been aggravated by digitalis; 7 had had digitalis but probably in doses that were unrelated to the tachycardia; 3 had had digitalis after the tachycardia without any aggravation of symptoms; and the remaining 3 had no digitalis at any time.

There had been no case in this series in which the ætiological role of digitalis was proved by therapeutic test, but it was probable in some of the cases. It is very likely, as Scherf and Kisch point out, that the quantity of digitalis is not the primary factor but rather the state of the heart muscle. One may go further and suggest that it is the state of the conducting tissues rather than of the contractile tissues that is of major importance.

Some cases of ventricular tachycardia could have been prevented. The method of rapid digitalization was popularized in 1920 and the danger involved has been generally realized only in recent years. The occasions for excessively rapid digitalization are not very common. Digitalis folia takes six hours before it begins to exert its maximum effect and yet it is extremely common to find the drug prescribed at three or four hourly intervals, thus allowing overdosage before the appearance of toxic symptoms. Six hourly intervals would be more rational.

Digitalis intoxication may arise, moreover, in a previously digitalized patient with the onset of diuresis and the liberation of large amounts of the digitalis that had been stored in the tissue fluids. It is quite possible to incriminate this mechanism in our cases. On looking through the reported cases and our own, the plea for more care in the use of digitalis seems wholly justified.

\section{Rate and Rhythm of the Paroxysms}

There is a great variation in the rate of the individual paroxysms. In this series the slowest is about 100 , while the most rapid is 270 . The average speed for 30 different paroxysms occurring in these 27 cases is 174. Campbell and Elliott (1939) found an average rate of 198 in their eight ventricular cases. There is no definite correlation to be found between the rate and the prognosis, although it is true that of the three patients with rates below 140, two died within a few hours while the third 
was alive two years after the episode, and that the extremely fast rates of 250 and 270 were found in patients with otherwise normal hearts.

It is not uncommon for both auricular and ventricular paroxysmal tachycardia to show some irregularity in the timing of the complexes in the first two or three beats before taking on the regular rhythm of the paroxysm. Three cases of this group illustrate a gradual change in rate, either speeding up or slowing down of the rate of the paroxysm. Case 18 (Fig. 10) showed a gradual increase in rate,

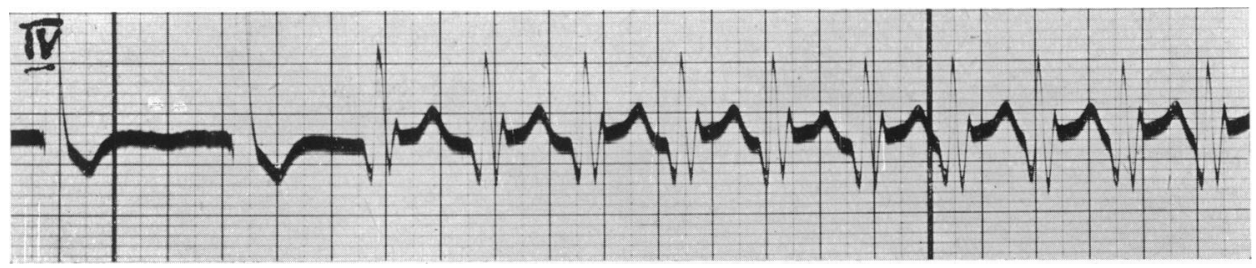

FIG. 10.-Case 18. Onset of paroxysmal ventricular tachycardia with abnormal ventricular complexes. There is a gradual increase in rate from 150 to 190 beats per min. Lead IV (old technique).

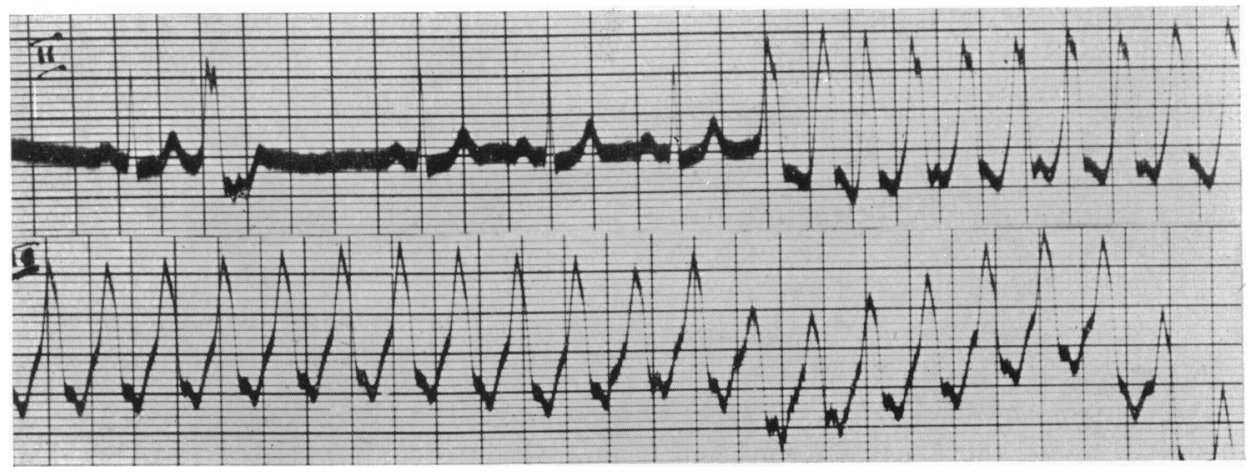

FIG. 11.-Case 26. Onset of paroxysmal ventricular tachycardia at a rate of 270 and gradual decrease to 220 beats a minute.

over about six beats from 150 until the rhythm appears to become regular at 190 . Case 24 also showed a slight tendency to speed up. Case 26 (Fig. 11) showed the opposite phenomenon, starting at 270 and slowing down over the space of many seconds to the rate of 220.

Levine and Strong (1923) reported that while the intervals were regular in paroxysmal auricular tachycardia, they showed slight irregularity in ventricular tachycardia. They reported and gave illustrations of three cases. Probably, however, their Case 3 was not ventricular tachycardia but auricular flutter with aberrant ventricular response, the auricles beating at a rate of 280-300 and the ventricules responding with $4: 3$ block and some slight regular variation in A-V conduction. This would explain the great regularity in the irregularity of the intervals. The second case also may not be ventricular paroxysmal tachycardia for it is unusual to find both auricular and ventricular paroxysms in the same patient and the records that are given of the two conditions are not from the same lead. In the example of ventricular tachycardia given, the onset of the paroxysm is shown, but it is impossible to be certain that there is no $\mathbf{P}$ wave hidden in the preceding $T$ wave or to identify any $\mathbf{P}$ waves in the ensuing paroxysm. Partly as a result of this article, there has arisen an exaggerated impression as to the irregularity of ventricular tachycardia. Irregularity of the nature or of the extreme degree shown in Levine and Strong's third case is extremely uncommon and should always lead to a search for some other mechanism.

Irregularity that can easily be seen on the tracings, is usually present in cases arising during auricular fibrillation (our Cases $8,10,17, \& 20$ ). It is present in an occasional case when the patient is very nearly dead (Case 12). Some irregularity is usually present in very short paroxysms, as in our own Case 23 where the measurements are shown on the electrocardiogram (Fig. 12). Among 15 of the tracings, however, in which there is a definite and prolonged paroxysm, 13 are perfectly regular, 10 as measured by calipers and time interval lines (Cases 3, 4, 5, 6, 14, 15, 19, 24, 25, \& 27) and the other 3 (Cases $1,11, \& 22$ ) as measured by the Lucas comparator. Case 13 appears to be irregular and the measurements of Case 2 show some slight irregularity. McKinnon (1934) also has found that the rhythm of the great majority of cases of paroxysmal ventricular tachycardia is perfectly regular. 


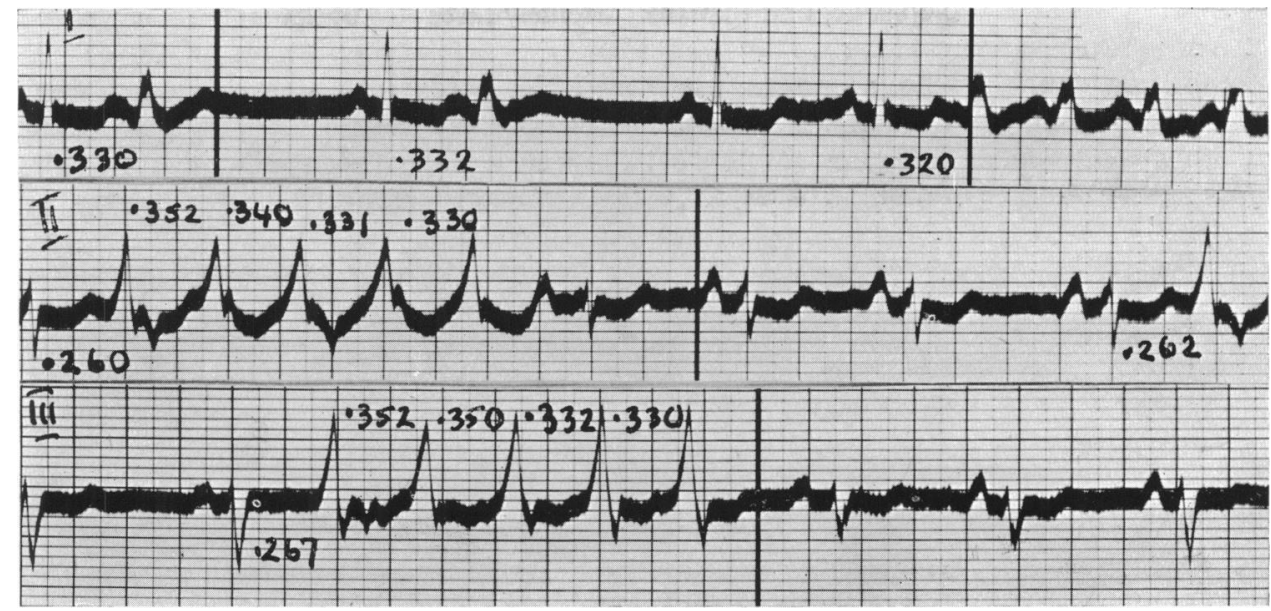

FIG. 12.-Case 23. Numerous short paroxysms of ventricular tachycardia. Comparator measurements show slight irregularity during the paroxysms. The onset of the paroxysms in lead II appear to take place at the same point in diastole on each occasion.

Campbell and Elliott (1939) also considered that any irregularity, which could be detected clinically, was more likely to indicate auricular flutter.

To sum up, the rhythm of ventricular tachycardia may be regular or slightly irregular, but there is no advantage in stressing the occurrence of irregularity, since marked irregularity is an exceptional finding.

\section{Duration of the Paroxysms}

The duration of the attacks in 13 of our patients was short, being a few seconds in the majority and less than an hour in the remainder. There were a number in whom attacks lasted several hours. The longest paroxysm appears to have been in Case 3 whose attack probably lasted over 4 weeks. He was in the hospital for one month prior to his death, and all treatment was ineffective in stopping the paroxysm. The longest case on record seems to be that reported by Elliot and Fenn (1934) in a girl, aged 19; this lasted 32 days.

\section{Facts and Theories as to the Production of Ventricular Tachycardia}

When there are numerous theories and each is supported by reliable workers, it is usually safe to say that none are satisfactory and that all contain some elements of the truth. In no subject is this more apparent than in the abnormal heart rhythms. Here elaborate theories have been built upon comparatively meagre knowledge of the human heart and a large amount of experimental work on the hearts of lower animals.

The most commonly accepted explanation has been that of a "circus " movement, based upon the experimental work of Mayer (1908). He caused a contraction wave to travel round a ring of tissue, cut from the bell of a jellyfish, by producing a temporary block in one portion. Garrey (1913, 1924), Mines (1913), Lewis, Feil, and Stroud (1918), De Boer (1920, 1927), and Wiggers (1940, 1941) are some of the workers who have put forward theories on the mechanism of the circus wave and modes of re-entry of the impulse to areas that were previously refractory.

Rothberger et al. $(1913,1922,1931)$ held that all the " ectopic" rhythms could be explained by differences in the rate of impulse formation, due to an ectopic focus beating at a rapid rate. This idea was incorporated in the theory of parasystole (Kaufman \& Rothberger, 1918), in which this focus was cut off from the remainder of the heart during normal rhythm by an area of block. The theory " tachisystole" was also put forward in various forms by Herring (1917), Haberlandt (1918), and Scherf (1928).

Geraudel $(1925,1926,1928)$ also held that the differences between the "ectopic " rhythms were only those of speed of impulse formation. He put forward the theory of "cardionectors," based upon the specialized blood supply to the S-A and A-V nodes and the complete independence of these nodes from one another. Any abnormal rhythm was due to the speeding up of one or the other of these two centres.

The origin of ventricular tachycardia is closely bound up with that of extrasystoles. Lewis (1925) 
pointed out that patients who present paroxysms of tachycardia constantly exhibit isolated extrasystoles during slow rhythm, which are usually of a similar nature to the complexes of the paroxysms and are provoked by similar agencies and terminated by similar means. For such reasons, he believed that paroxysmal tachycardia and extrasystoles were alike phylogenetically. He summed up much of the experimental work and present-day conception of extrasystoles. "In the frog all parts of the heart muscle are capable of originating rhythmic impulses. Many parts of the mammalian heart will initiate beats under particular circumstances, but there is little evidence that those containing no special tissue can keep the heart beating rhythmically in situ. There is little evidence to suggest that extrasystoles can spring from the ventricular muscle as opposed to the Purkinje system and there is some evidence to suggest the latter as their usual starting point."

Clinically, extrasystoles and paroxysmal tachycardia are very closely related, while in the auricle, the dividing line between paroxysmal tachycardia and flutter, and flutter and fibrillation, is difficult to define. On these grounds alone, there would be ample justification for regarding the basis for all these four rhythms as essentially the same. This view has been put forward by many workers (Kauffman \& Rothberger, 1917; Garrey, 1924; Wiggers, 1937; and others).

However, no one as yet has laid the foundation upon which any theory for the tachycardia can be built, for few have suggested or shown any adequate reason for the S-A node during normal rhythm or the A-V node during heart block to continue to send out impulses. To postulate other centres, as in some of the theories, seems to introduce unnecessary complications. All the theories have been built up on circumstantial evidence and, although strong and undoubtedly correct in some instances, there has never been any direct proof for any of them. The experimental work upon which each theory has been built has always called forth a certain amount of justifiable criticism from other workers in the same field. Further, there has been no very convincing evidence put forward to show why the abnormal rhythm commences, why occasionally a single beat will cause a paroxysm of fibrillation and not tachycardia, why a paroxysm once started should ever cease abruptly, or why an extrasystole should not precipitate a paroxysm of tachycardia in every case.

The basic fact, upon which the theory of the ectopic origin of the ventricular premature beat has been founded, is the aberration of the ventricular complex. Very little attention has been paid to the aberrant ventricular complex on the occasions on which it is quite certain that the impulse has reached the ventricles through the A-V node. Lewis $(1911)$ and White et al. $(1916,1928)$ have called attention to such cases and have shown conclusively that the earlier the auricular ectopic beat, the more possibility there is for the resulting ventricular response to show some degree of aberration. The sole reason for such an occurrence appears to be the degree of prematurity, and in any tracing that shows numerous ventricular extrasystoles, it will be seen that the earlier in diastole that the beat arises, the more aberrant become the ventricular complex.

In published tracings of induced extrasystoles (e.g. Lewis, 1925), the shape of the complexes also varies with the degree of prematurity. In the examples given, no complex is the same and none arises at the same time after stimulation. While these observations in no way disprove the original contention that the extrasystoles arise from various points in either ventricle, the experiments will also support the theory that the aberrant ventricular complexes are due to stimuli arising from a single centre at various times in the cardiac cycle, possibly in the case of the ventricle, the A-V node itself.

Direct stimulation of the human heart (Barker, Macleod, \& Alexander, 1930; and Lundy, Treiger, \& Davison, 1939) has not clarified the position, as it is possible to produce similar shaped complexes by stimulation of given points either in the right or left ventricles.

Consideration of the causes and precipitating factors of the cases of auricular tachycardia and fibrillation makes it clear that reflex action (possibly through temporary alterations in the physicochemical state of the conducting systems and the chemical mediators of the autonomic nervous system) rather than any organic disease plays by far the major role in their production. In the cases of ventricular tachycardia, coronary heart disease is present in 80 per cent of our cases. If, however, one takes into consideration the preponderant amount of coronary heart disease that comprises the material of the laboratory of the Massachusetts General Hospital, it seems evident that coronary heart disease by itself can only play a minor role. Infarction of the cardiac muscle with various local upsets in the coronary circulation should provide numerous occasions for the escape of the ectopic rhythm centres and initiation of various types of local block, etc. The fact remains that it does not do so in the vast majority of cases.

In recent years, evidence has been accumulating on the supernormal phase of the cardiac cycle and its possible role in the production of abnormal rhythms.

In 1912, Adrian and Lucas applied the term "supernormal phase" to a condition occurring in injured excitable tissue. They found that there was a short period, during recovery from a previous stimulus, in which the tissue became hypersensitive to new stimuli. They also showed that this supernormal excitability of nerve tissue was accompanied by a supernormal variation in conductivity. 
Adrian in 1920 again confirmed this work and showed its presence in the frog's ventricle. De Boer (1920) noted that a single stimulus, applied to a desanguinated frog's ventricle some time after the refractory period was over, caused an extrasystole, whereas a stimulus applied immediately after the refractory phase caused a " continuous circulation," though he did not postulate a supernormal phase.

In 1924, Lewis and Master were the first to apply this conception to the human heart. In one of their cases, a case of paroxysmal heart block, the $\mathbf{P}$ waves were only conducted to the ventricle at a phase of the refractory period which is usually totally unresponsive. This phase lay between the summit and the end of the $T$ wave. They likened this to the supernormal phase of Adrian and Lucas. In 1925, Ashman showed its presence in the conduction tissues of the turtle and, together with Herrmann in 1926, suggested that a case of paroxysmal complete heart block could be explained by such a mechanism.

Since then a number of other cases have been described (Jervell, 1934; Luten D, \& Pope, 1930; Scherf \& Schott, 1939; and Kline, Conn, \& Rosenbaum, 1939). Although doubt has been cast upon the interpretations of some of the tracings, it now seems to be accepted that the supernormal phase does occur at various points in the human cardiac cycle, and it may account for both A-V and $\mathrm{V}-\mathrm{A}$ conduction in certain cases.

Eccles and Hoff (1934) have shown experimentally that a supernormal phase may occasionally be present in the pacemaker of the heart.

Erlanger and Gasser (1936) have shown the existence (in nerve) of certain after potentials, long after the period of excitation accompanying the propagation of the impulse, and that these potentials are associated with various phases of the recovery process. They also found that the supernormal phase which follows the relatively refractory period was associated with a negative after potential. This phase is very easily affected by many simple factors, such as asphyxia and alteration of the acidbase equilibrium. It might be noted here, in connection with the experimental production of ventricular fibrillation, that Schlapp (1932) showed that alkalosis, produced by overventilation, sensitized the ventricle to the action of adrenaline. Segers (1939), working with the frog's auricles, has also shown that the hyperexcitable phase is facilitated by adrenaline and sodium bicarbonate, and suppressed by ammonium chloride, potassium, and acetylcholine.

Gasser noted that nerves which show a marked supernormal phase were likely to respond to a single stimulus by prolonged repetitive discharge during which each succeeding discharge occurred at the height of the supernormal phase. He explained this phenomenon on an inherent residing subliminal stimulus which was thus able to give rise to spontaneous activity when the supernormal phase was present.

This reasoning has been applied to the Purkinje fibres of the heart by Goldenberg and Rothberger (1936), and it is suggested that the subliminal stimulus gives rise to an extrasystole whenever the supernormal phase occurs. By applying the idea of repetitive discharges, it is possible to suppose that an attack of paroxysmal tachycardia might occur.

Nahum and Hoff $(1938,1939)$ investigated the supernormal phase in higher animals, in cats, dogs, and a chimpanzee, and found that it occurred between the descending part of the $T$ wave and the end of the $U$ wave. They then investigated bigeminal rhythm in man and showed that in extrasystoles as a whole, the majority occurred on the descending limb of the $T$ wave and in the area occupied by the $U$ wave. Only a few occurred outside the supernormal area and these, they suggested, were of the nature of ventricular escape.

They point out that the ventricular conduction system possesses an inherent automaticity, usually subliminal. If, however, a marked supernormal phase develops, this latent stimulus may give rise to an extrasystole. Should the phase be continually present, bigeminy or even paroxysmal tachycardia might be produced. Even in the presence of a supernormal phase, should the internal stimulus be insufficient, no response may be expected: also should there be heightened automaticity of the conduction system, discharge would occur without the aid of the supernormal phase. Segers puts forward a similar view.

It is interesting to note that Lewis (1925) had postulated a " critical" period as an essential part of the mechanism to explain contrary effects produced by the vagus and sympathetic nerves and drugs such as chloroform, atropine, quinidine, and potassium salts.

We have been fortunate in securing a record of the onset of a paroxysm in 17 of our patients. The onset in 14 of these was at or near the end of the T wave (e.g. Fig. 8).

In Cases 21 and 23 (Fig. 13 and 12), there were a number of short paroxysms and in each the ventricular tachycardia, as measured by the Lucas comparator, started at the same point in diastole. The other three cases appeared to be initiated by an auricular complex. That these were paroxysms of ventricular tachycardia was shown by the presence of $P$ waves at a slower rate during the paroxysm. In Case 13, the P-R interval was $0.32 \mathrm{sec}$. shortening to $0.18 \mathrm{sec}$. prior to the paroxysm, whilst in the other, Case 19, the P-R interval preceding the paroxysm was variable. In both, however, the occur- 
rence of a $P$ wave might be accounted coincidental, as the paroxysm commenced in the period of the cycle that may be associated with a supernormal phase. The auricular rate was also rapid in both. The third case showed a paroxysm beginning with a shortened P-R interval and a ventricular complex similar to the complexes seen in the Wolff-Parkinson-White syndrome (Fig. 14). It is only after this initial aberrant complex that the true paroxysm appears to begin.

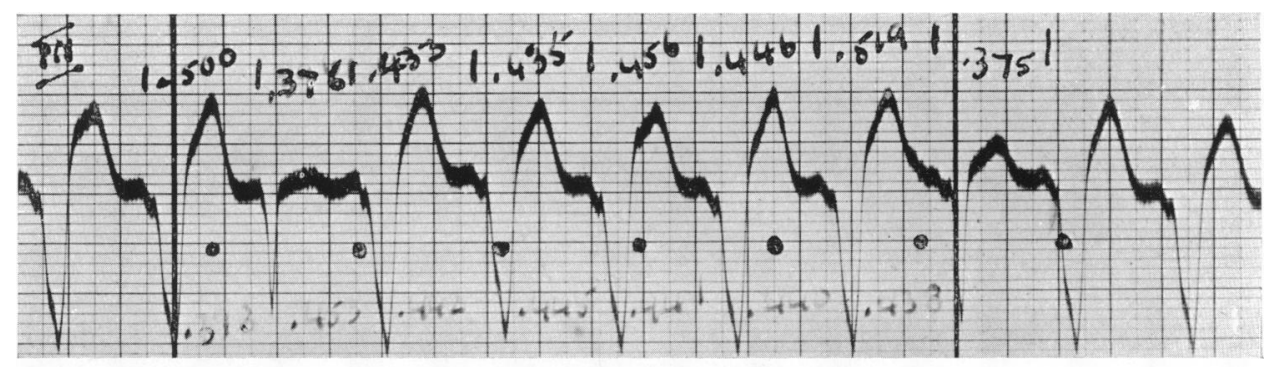

FIG. 13.-Case 21. Lead III taken during repeated paroxysms of ventricular tachycardia of varying duration; ventricular rate 140 and auricular rate 120 . Comparator measurements made as to the time of onset in four successive paroxysms, were probably identical, $\mathbf{0} \cdot 378,0 \cdot 376,0.375$ (the last two shown in the figure), and $0.373 \mathrm{sec}$.

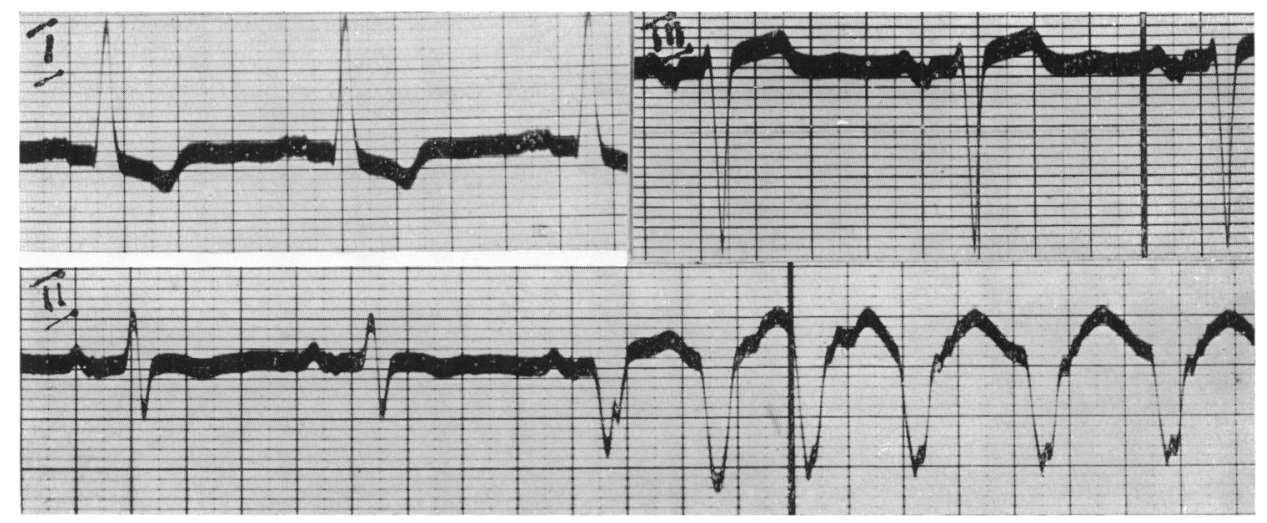

FIG. 14.-Case 10. Leads I and III (above) show normal rhythm with a P-R interval of 0.21-22 sec. Lead II (below) shows the onset of a paroxysm of ventricular tachycardia. The paroxysms is preceded by a $P$ wave and a shortened $P-R$ interval of $0.18 \mathrm{sec}$. The first ventricular complex appears to be different from the remainder of the paroxysm.

In Cases 22 and 24, the presence of a short P-R interval and slurred QRS complex was noted in the breaks in the tachycardia for one and two beats before reverting to the paroxysm again (Fig. 1). These findings suggest an abnormal excitability at the A-V node, and support rather than refute the hypothesis that a supernormal phase of the bundle and $\mathrm{A}-\mathrm{V}$ node supplies the conditions for the onset of paroxysmal tachycardia.

To sum up then, there is evidence accumulating to suggest that extrasystoles can occur during the supernormal phase of a site of stimulus formation: when this happens, the complex is of abnormal type and in classical terminology would be designated as a right or left ventricular extrasystole. This phase is dependent upon factors that are essentially similar to those which determine the onset of paroxysms of tachycardia (changes in general metabolism, adrenaline, acetylcholine, potassium, etc.). This fact, together with the usual time of onset of the paroxysms, seems to offer some evidence in favour of the "supernormal phase" theory of paroxysmal tachycardias. There appears to be no necessity to postulate centres for the source of the ectopic rhythms other than the A-V node and the bundle, since aberration of the complexes are equally explicable on the basis of prematurity alone as by origin from ectopic focus.

At the moment, however, the conception of " re-entry" of the original stimulus through an area that was refractory at first, particularly as put forward by Wiggers $(1940,1941)$, is the most generally accepted explanation of extrasystoles, tachycardia, and the inception of circus movement. 


\section{Ventricular Paroxysmal Tachycardia with Alternating Complexes}

There were four cases in this series showing alternation of the ventricular complexes (Fig. 15). Three of them (Cases 1, 9, \& 24) have previously been reported. Three of the four had severe coronary disease, while the fourth (Case 24 ) had only very slight alternation and had a heart otherwise normal.
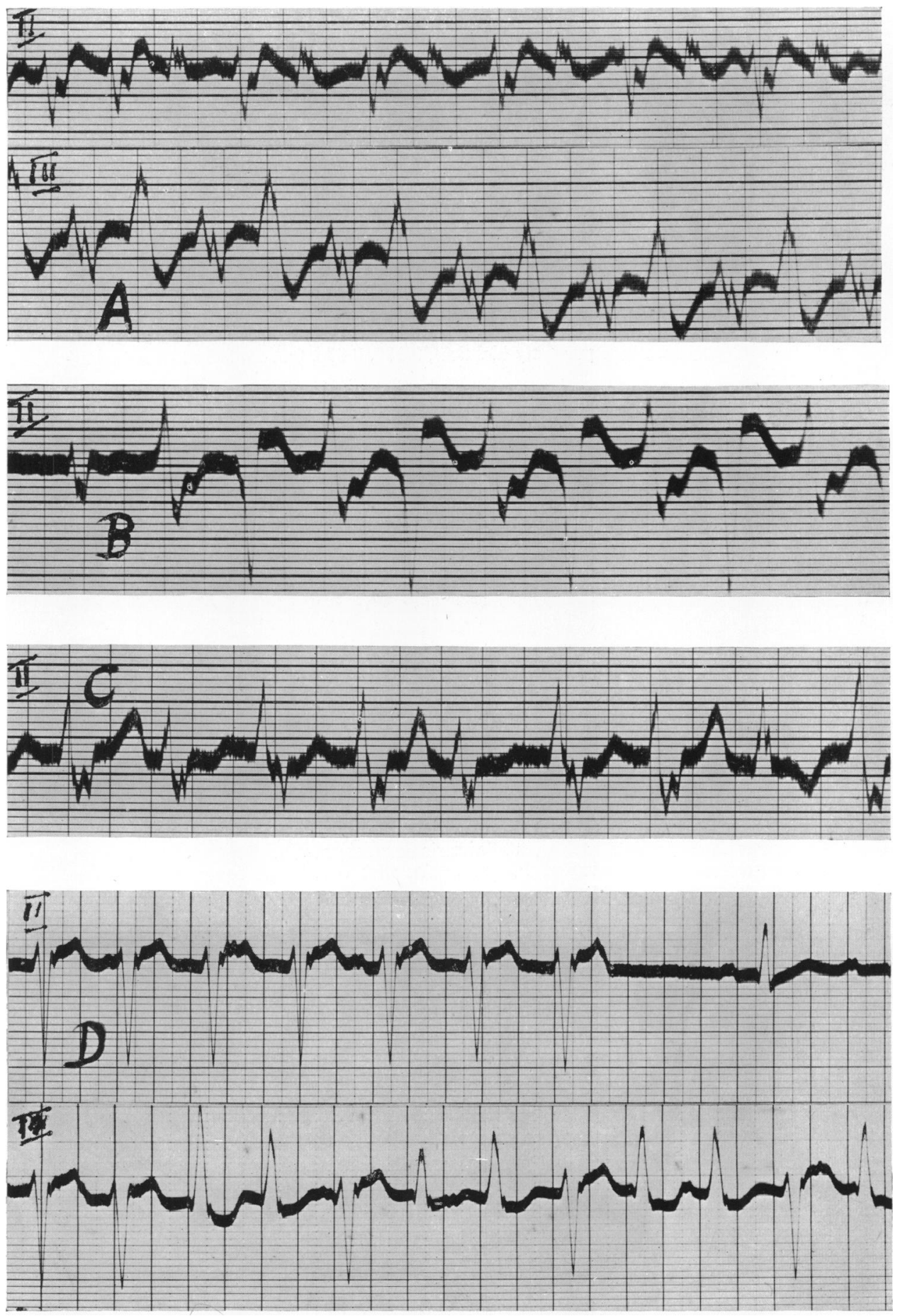

Fig. 15.-(A) At the top, leads II and III (Case 1), and (B) lead II (Case 9) show well-marked alternation. (C) Lead II (Case 24) shows very slight alternation. Electrocardiograms from these three cases have been published more fully elsewhere. (D) Leads II and IV (Case 2) shows the end of a paroxysm, and in the second strip, regular alternations of the ventricular complex. P waves are well shown. 
The three cases with coronary heart disease died within a few days, while the fourth was still alive recently, twelve years after the electrocardiogram in question was taken. Digitalis had been given in excessive doses to two cases while it may or may not have played a part in the third case with coronary disease.

Various hypotheses have been put forward from time to time to explain the alternation. The tachycardia may arise from a single centre above the bifurcation of the bundle of His and the alternation may be the result of changing right and left branch block (Luten, 1924). The Purkinje fibres themselves may be refractory in alternate ventricles with successive beats so that alternate dextroand lævo-cardiograms preponderate (Marvin, 1928). The alternation may arise as the result of the interplay of two separate rhythms (Marvin); and finally Palmer and White suggested the interplay of two separate circus movements in the ventricular muscle in alternate directions, but arising from the same site (figure of eight circus).

In several reported cases not only is there alternation in the complexes but also in the time intervals between the complexes. For example, Palmer and White carried out careful comparator measurements in two of the cases that are included in this group. The measurements they produced are striking in showing this alternation, and on this account they considered that alternation of the right and left branches was improbable owing to the difference in timing of the two types of complex.

It is possible, however, that such variations may be due to the inability to measure comparable points on the successive complexes. Neither the onset nor the peak of the $\mathbf{R}$ wave is identical in timing in two successive but different complexes. The beginning of the ventricular complex would be the ideal point to take comparator measurements from, and this is impossible to determine without the use of simultaneous leads. White, Leach, and Foote (1941) have shown conclusively that the beginning of the QRS complexes are frequently isoelectric in one of the leads. Marvin (1928) on the basis of irregularity of the timing of the complexes suggested that this indicated that the pacemaker must reside within the ventricles, and supposed that the resulting irregularity of the complexes was due to the varying time relations between the dextro- and lævo-cardiograms. The criticisms as to measurements may be applied to his tracings. It is probable that in all these cases, in spite of apparent variation in time intervals, the beats are regular.

Normal sino-auricular rhythm with alternating bundle branch block has been reported (Korns, 1922; and Scherf \& Kisch, 1939). Since alternation of the ventricular complexes can take place in response to an impulse of supraventricular origin, and since the timing of the onset of the ventricular complexes has not yet been satisfactorily determined, Luten's explanation still seems the most rational. He wrote, " Digitalis intoxication results in a tachycardia which originates at or near the bifurcation of the main stem of the bundle. The action of the drug has also impaired to a considerable extent the conductivity of the bundle branches. An impulse is then transmitted over one (the right) branch but finds the other (the left) for the most part unable for the moment to transmit it. A small strand in the impaired left, however, does transmit the impulse but at a slower rate. This gives the picture of defective branch conduction. The next rhythmic impulse finds the bulk of the left branch restored and ready for conduction, but the bulk of the right branch has not yet recovered and so fails to transmit the impulse." Marvin (1928) had criticized such an idea on the basis of finding in one of his cases permanent bundle branch block, stating that in such a case, two centres would have to be present with one below the site of the branch block. Yater (1938), however, has shown that in such cases both bundles are severely damaged and that the electrocardiographic findings are merely an index of which branch is the most severely affected. Scherf and Kisch (1939) also believe that some, if not all, of their 18 cases can be explained by variations in conduction of impulses arising at a single point.

Therefore, on account of the reasonings we have already given, it is possible to suppose that the centre for ventricular paroxysmal tachycardia with alternating complexes lies in the bundle of His and in fact may be situated in the A-V node itself.

\section{PRognosis}

For the estimation of prognosis, the cases must be divided into two groups, those with organic heart disease and those with apparently normal hearts.

The occurrence of ventricular tachycardia in organic heart disease is a serious prognostic sign. Strauss (1930) found that of 50 cases with serious organic heart disease, 40 were dead within three hours to six months of the onset of the tachycardia, with an average duration of life of 24 days. The great majority of these received no specific medication.

The French workers, whose views have been well summarized by Froment (1932), hold that there are two types, a benign type of repeated ventricular extrasystoles occurring in young subjects (e.g. Cases $24 \& 27$ ); and the commonest type, a terminal or pre-fibrillation type which is the forerunner of death. 
In our group of 21 cases of coronary heart disease, there were four still living at the time of writing. Two of them were extremely active, the time since the first paroxysm of tachycardia being two years in each case. Of the other two cases, one was a semi-invalid, four months after the occurrence of the paroxysm, and the other was crippled with vascular disease of the legs and had only just been discharged from the hospital four weeks after the tachycardia.

In our remaining 17 cases of coronary heart disease, death occurred within periods ranging from a few hours to eighteen months. Of these, there again seemed to be two groups, the one slightly larger comprising the patients dying within the first three weeks after the event, and the other in which they recovered for a while from that particular crisis and died some months later, in some cases suddenly and unexpectedly. While some of the first group would have died as a result of their coronary thrombosis, one or two might perhaps have survived a few months longer had treatment with quinidine or quinine been instituted. The exact length of survival can be seen in the appendix. The three cases with alternation of the ventricular complexes and coronary disease all died within two weeks. This is in accord with the experience of reported cases.

There are five cases of otherwise normal hearts in our group. Two of these were known to be living and well (Cases $23 \& 25$ ) at two and nine years respectively after the detection of the tachycardia. Case 26 had not been traced. Case 24 was alive in 1937, 12 years after the detection of the arrhythmia and 25 years after the probable onset; we were unable to get in touch with him more recently. Case 27 probably has an interventricular septal defect and also shows short P-R intervals and wide QRS complexes during normal rhythm; she was alive and well 14 years after the onset.

Case 15 might possibly throw doubt upon the diagnosis of the five irritable normal hearts. This patient, a woman aged 42 years, was diagnosed as having an irritable normal heart, but follow-up study revealed that she died three to four years later. The mode of death was not known but she has been classed as a case of probable coronary heart disease elsewhere in this paper. She was under observation for one year, during which treatment had little effect upon the frequency of the attacks. Occasionally similar cases have come to autopsy, e.g. Scherf's patient (McKinnon, 1934) who had paroxysms over five years, died with congestive failure, and had a heart in which there was no demonstrable disease. Campbell and Elliott $(1939$, p. 147) reported two similar cases. In these, both males aged 17 and 21 years, the paroxysms had been present over periods of five years and six months respectively before sudden death occurred.

The prognosis then is generally poor though exceptions are met with. A few cases with organic disease will manage to survive and young patients with apparently normal hearts have a good chance of lengthy survival.

\section{Treatment of Paroxysm}

Quinidine appeared to help the two patients with coronary heart disease who lived longest and at last account were still actively working. In two cases it seemed to counteract the effect of digitalis very rapidly, although not averting the fatal issue in either case. No effect could be obtained in Case 3 who was given a minimum dose of 18 grains daily and a dosage pushed to toxic levels on three occasions during the month he was in hospital.

Earlier writers (Levy, 1922; Drury et al., 1922; and Levine, 1927, etc.) stressed the possibility of producing ventricular fibrillation with quinidine. Cases, too, have been reported in which the ventricular tachycardia only ceased on its withdrawal. Such cases, however, are rare and some of the examples reported have been attributed to quinidine wrongly. Occasionally perhaps the heart is in such an irritable state that any cardiac drug will provide the necessary stimulus for the tachycardia. We believe then, that the possibilities of inducing ventricular fibrillation should never weigh against the use of quinidine.

In our group of cases quinidine in various dosage has been given only by mouth. For example, Case 19 received 3 grains at half-hourly intervals for five doses before the rhythm became normal after an attack which lasted six hours. Quinidine may be given in 3 to 6 grain doses every two to three hours until either restoration of normal rhythm occurs or signs of intolerance develop. The necessary dose shows a great variation from patient to patient. When the rhythm does become normal, a daily maintenance dose should be continued for three to four months at least. There appears to be no contra-indication to the prolonged administration of quinidine. Case 21 and Case 23 both took 3 to 6 grains of quinidine daily for over two years and have shown no ill effects from the drug; other patients have taken even larger doses of the drug for many years without harm.

Treatment with intravenous injections of quinidine has been reported on favourably by Hepburn and Rykert (1937). They treated 9 cases with intravenous quinidine, 50-60 grains dissolved in 500 c.c. of 5 per cent glucose and given at a rate of 100-120 c.c. an hour. They pointed out that of these nine cases six were alive at the time of writing, for period up to four years since the tachycardia, 
whereas only one out of nineteen cases who were not so treated lived longer than 15 days. Others (Bunn, 1932 and Battro, 1937) have also had good results.

The most convenient and effective method of stopping ventricular tachycardia that has proved refractory to drugs by mouth is, however, the use of quinine dihydrochloride by intramuscular injection, 5 c.c. of aqueous solution containing $7 \frac{1}{2}$ grains $(0.5 \mathrm{gram})$ given every two hours until normal rhythm is restored or severe cinchonism results (Riseman \& Linenthal, 1941).

Mecholyl (acetyl-B-methylcholine chloride) has been used with good results in paroxysmal auricular tachycardia, and in such cases, ventricular standstill is not uncommon. Mecholyl has also been used experimentally by Nahum and Hoff (1934) to prevent the onset of ventricular tachycardia induced by the action of benzol, adrenaline, and electrical shocks. It is not surprising, therefore, that it has been used for the treatment of ventricular paroxysmal tachycardia; Stern (1937) reported failure in two cases so treated.

It has been suggested (Hall, 1939), however, that acetycholine causes coronary artery spasm and certainly in some patients, its administration causes symptoms well-nigh indistinguishable from those of angina pectoris. There is clearly an element of danger in using such a drug in hearts of the sort usually found in patients with ventricular paroxysmal tachycardia. We believe, therefore, that if this drug must be used, it should be given only to young patients (e.g. Cases $24,25, \& 27$ ) who have otherwise normal hearts.

There will remain a few patients in whom the attacks of ventricular tachycardia can be controlled only by the administration of full doses of both digitalis and quinidine (e.g. Scherf and Kisch's case).

\section{SUMMARY}

We have reported 27 cases of ventricular paroxysmal tachycardia: 24 of these were found in a review of some 51,000 plates and films taken on about 25,000 patients in the Cardiographic Laboratory of the Massachusetts General Hospital over a period of 25 years from 1914 to 1939.

The criteria for diagnosis were the electrocardiographic findings. Fulfilment of any one of the following four points justifies the diagnosis.

1. The presence of $\mathbf{P}$ waves at a slower rate than that of abnormal QRS waves during a paroxysm of tachycardia.

2. A paroxysm of abnormal ventricular complexes, that is, three or more, occurring during auricular fibrillation.

3. The onset of the tachycardia with an abnormal ventricular complex.

4. Close resemblance of the complexes of ventricular premature beats to the complexes occurring during paroxysmal tachycardia.

Coronary heart disease was present in 22 of our 27 cases, 4 had apparently normal hearts, and 1 was thought to have a congenital ventricular septal defect. There were 17 males and 10 females, the youngest being aged 18 years and the oldest 81 years.

Digitalis had been administered to 13 of the 27 cases before the onset of the tachycardia. It was probably the chief ætiological factor in at least 5 of these cases.

It is suggested that abnormalities of the ventricular complexes of premature beats are responses to stimuli arising in the A-V node or bundle or main branches at a point in the cardiac cycle when the conducting tissues are still partially refractory. The onset of ventricular tachycardia was generally in the part of the cycle that has been associated with the supernormal phase. The mechanism of ventricular tachycardia with alternating complexes may be due to abnormalities in conduction along the bundle branches in response to impulses arising in the A-V node.

The prognosis is generally, but not always, poor. Only two patients with coronary heart disease survived longer than two years after the first attack. Five patients with hearts otherwise normal have survived to date, periods varying from two to fifteen years.

Quinidine or quinine should be used in adequate dosage in the treatment of the attack, being given either by mouth, intramuscularly, or intravenously. Quinidine sulphate is most conveniently given by mouth in the dosage of 6 to 9 grains every 2 hours for 5 to 6 doses under close observation and preferably with electrocardiographic control. If quinidine fails, quinine dihydrochloride, grains $7 \frac{1}{2}$ subcutaneously, every 2 hours, is recommended to stop the paroxysm and even to save life. A daily maintenance dose of quinidine by mouth ( 3 grains of the sulphate, 4 times a day) may be continued for prophylactic purposes for an indefinite time.

\section{Appendix of CASE Notes}

In all these cases, the age given has been the age at death or, in the cases of those living, the age at the completion of the survey. EC. is used for electrocardiogram. 
Case 1 (Fig. 15 B). A man, aged 50 years, had angina pectoris for three years and an attack of coronary thrombosis ten days before admission to hospital. There was slight congestive failure and a pulse rate of 190 with a B.P. of 140/105. On admission, he was given large amounts of digitalis, 27 grains in all, but died 40 hours after entry. Autopsy showed a heart weighing $545 \mathrm{~g}$. with signs of fresh infarction at the apex of the left ventricle; a recent thrombus was present in the descending branch of the left coronary artery.

Case 2 (Fig. 15 D). A man, aged 80, was admitted in marked congestive failure. B.P., 160/90. Fairly rapid digitalization was carried out, 24 grains in 84 hours in this man who weighed but 125 pounds. The presence of ventricular tachycardia with alternating complexes at the end of this period was noted. EC., slight prolongation of the P-R interval and slight sagging of the S-T segments in leads II and III gave some indication of the digitalis effect. Death occurred 48 hours later. At autopsy the heart weighed $575 \mathrm{~g}$. and showed diffuse coronary sclerosis.

Case 3 (Fig. 16). A man, aged 48, was treated for hypertension and coronary heart disease, following an attack of coronary thrombosis three years previously. After a cold, he developed congestive heart failure and ventricular tachycardia. Digitalis, 20 to 30 minims, t.i.d., had been administered

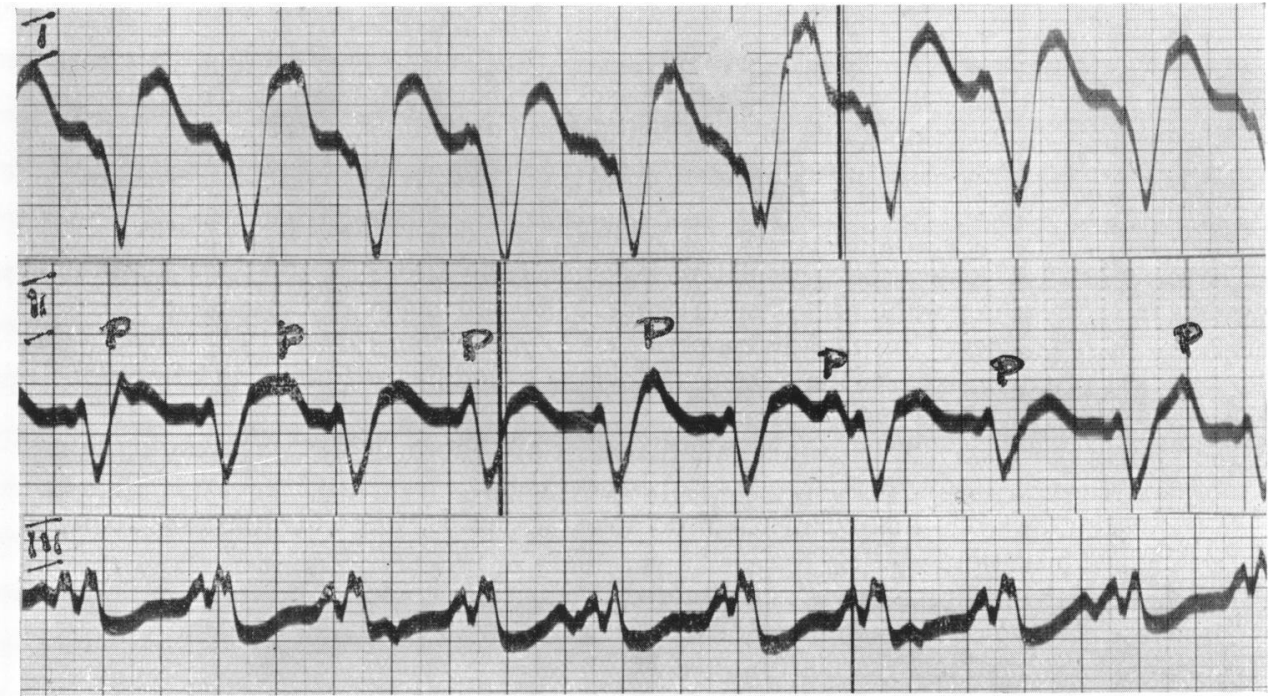

Fig. 16.-Case 3. Ventricular tachycardia at a rate of 140 ; auricular rate, 95 . This attack lasted for more than twenty-eight days, probably for six weeks, terminating in the patient's death.

for one month prior to admission. No treatment, even quinidine in toxic doses, availed to stop the rhythm. He died one month after admission when digitalization was again being attempted. Ventricular tachycardia had been present for about six weeks. Autopsy showed a heart weighing $700 \mathrm{~g}$. Most of the anterior wall of the left ventricle and lower part of the interventricular septum had been replaced by fibrous tissue.

Case 4. A man, aged 70, who had stopped work a few weeks previously owing to shortness of breath, was admitted to hospital with Cheyne-Stokes breathing and marked congestive failure. EC., ventricular tachycardia. He died 12 hours after admission. Digitalis, 6 grains, was given in hospital but the dosage given over the previous three weeks was not known. Autopsy showed a heart weighing $700 \mathrm{~g}$. with diffuse coronary atherosclerosis.

Case 5. A man, aged 60, had had large doses of digitalis, 4.5 grains daily, for one week which should have been enough to complete digitalization, but he continued with 3 grains daily for a further week at the end of which time he had diarrhœa and attacks of ventricular tachycardia. A further 6 grains were given in hospital. He died suddenly and unexpectedly 20 hours after admission, quite possibly the result of ventricular fibrillation. His heart weighed $680 \mathrm{~g}$. and showed moderate left ventricular hypertrophy and diffuse coronary atherosclerosis. EC., very little evidence of digitalis intoxication.

Case 6. A man, aged 55, was, compared with some of the other cases, in very mild heart failure. Massive doses of digitalis, however, !had been given on admission, 54 gains in 120 hours, at the end of which time he showed ventricular tachycardia. Digitalis had been continued in spite of the continuance of this arrhythmia until his death seven days later. Shortly before death an attempt was made to control the attacks with quinidine. The effect of the digitalis on the EC. was to produce periods of bradycardia during which there was complete A-V dissociation, the S-T segments showing very little deviation. 
Case 7. A man, aged 53, was admitted for fainting attacks following an attack of abdominal pain two months previously. A diagnosis of coronary thrombosis and attacks of ventricular tachycardia was made. He died 18 months later while taking an automobile test. No autopsy.

Case 8. A man, aged 57, had suffered with symptoms of hypertensive heart disease for over a year. He was admitted to the hospital after the onset of auricular fibrillation and an exacerbation of his symptoms: B.P., 220/120. He was kept on a maintenance dose of digitalis with rest periods and died fourteen months later in congestive failure. No autopsy.

Case 9 (Fig. 15 B). A man, aged 45, had been admitted to the hospital seven years previously with congestive failure, and recently with auricular fibrillation and congestive failure of two weeks' duration; he had been in fairly good health since his first admission; B.P., 130/100. He was given 30 grains of digitalis over the first 48 hours when the EC. revealed ventricular tachycardia with alternating complexes. He developed pneumonia and died 7 days later. No autopsy.

Case 10 (Fig. 14). A man, aged 66, was treated for hypertension and coronary heart disease with a daily maintenance of digitalis for four years prior to his death, being admitted to hospital on three occasions for congestive failure. EC. showed ventricular tachycardia during his last admission to hospital, 8 months prior to his death. No autopsy.

Case 11. A man, aged 49, was admitted complaining of abdominal pain for which an exploratory laparotomy was performed. He then developed congestive heart failure and cardiographic changes of coronary thrombosis. Following digitalization, 42 grains in 14 days, he had an attack of ventricular paroxysmal tachydardia of 6 to 8 hours' duration. Digitalis was continued with normal maintenance dose. He died 8 months later. No autopsy.

Case 12. A woman, aged 44, developed a pelvic abscess, following an operation for hyperthyroidism and a diagnostic dilatation and uterine curettage. During convalescence she had a cerebral embolism, and an EC. during this upset showed the presence of ventricular tachycardia. She died a few hours later. No autopsy.

Case 13. A man, aged 60, was first seen by us in a state of digitalis intoxication, having for the past three-and-a-half months taken 1.5 grains three or four times daily. When seen he had been semiconscious and delirious for nearly four days while his pulse, normally 70 , showed numerous runs ot tachycardia at the rate of 150 . The ventricular tachycardia showed no signs of stopping after omitting the drug for two days but stopped immediately with quinidine. The EC. then showed prolonged A-V conduction, $0.32 \mathrm{sec}$. (six months previously, $0.24 \mathrm{sec}$.). He was thought to be well on the way to recovery when he developed signs of lung involvement. He died six days after the cessation of digitalis.

Case 14 (Fig. 17). A woman, aged 62, had stopped working twelve months previously owing to shortness of breath. One week prior to entry, she had had an attack of fainting and had been weak
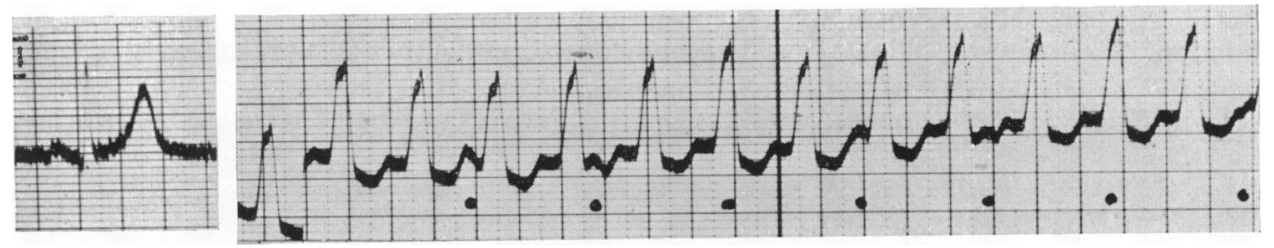

FIG. 17.-Case 14. Ventricular paroxysmal tachycardia rate 160 . P waves are shown at a rate of 100 , and are shown with dots.

ever since. On admission she had congestive failure and a rapid pulse rate which was shown by EC. to be ventricular tachycardia. Digitalis given after onset, 36 grains in 4 days, and thereafter maintenance dose of 1.5 grains. Follow-up study two years later revealed that she had died but the date and details were unknown.

Case 15. A woman, aged 42, was admitted to the hospital on account of a neck swelling and a feeling of compression there, of one year's duration, and palpitation of six months' duration. There was a goitre but no signs of hyperthyroidism were detected; EC. showed ventricular paroxysmal tachycardia. Hemi-thyroidectomy was performed for pressure symptoms. She died more than eighteen months later; the details were unknown.

Case 16. A woman, aged 52, had symptoms of hypertension and coronary heart disease for one year. B.P., 210/100: taking small and varying quantities of digitalis for the previous five months. EC. whilst in hospital showed attacks of ventricular tachycardia. She made very little improvement and died at home three months later. No autopsy.

Case 17 (Fig. 7). A man, aged 54, had suffered with auricular fibrillation for seven years, for which he had been taking small quantities of digitalis. His symptoms had been more marked over the previous five months; EC. showed short runs of ventricular tachycardia. His subsequent fate is unknown. 
Case 18 (Fig. 10). A woman, aged 59, had been taking 2 to 3 grains of digitalis daily for a year and then three weeks previously had increased her dosage to 6 grains daily. She was admitted in marked congestive failure, complaining of much blurring of vision, weakness, and marked loss of appetite. B.P., 160/110. EC. showed ventricular tachycardia and markedly depressed S-T segments in leads II and III. She improved somewhat with diuretics, on the omission of digitalis. She died at home about four weeks later.

Case 19. A man, aged 63, had suffered with angina pectoris for 18 years and was admitted owing to an increase of symptoms and tachycardia for the previous three weeks. Following $1 \cdot 1$ gram of digitalis over 36 hours, he developed ventricular tachycardia which eventually was controlled by large doses of quinidine, a maintenance dose of which for the next three months completely controlled the arrhythmia. On re-admission, 18 months later, another paroxysm of ventricular tachycardia of twenty hours' duration was again controlled by quinidine. Digitalis probably played no part in this case.

Case 20. A woman, aged 72, had been treated for arthritis for many years. Four years previously she had been admitted to the hospital with coronary thrombosis. Following an increase in her cardiac symptoms, she was readmitted. EC., auricular fibrillation with short runs of ventricular tachycardia. The tachycardia was noted again following digitalization. She was still alive four months later, taking a daily maintenance dose of digitalis.

Case 21 (Fig. 13). A man, aged 72, had suffered with a duodenal ulcer for over 30 years. Two years previously he suffered a coronary thrombosis and during convalescence he developed ventricular tachycardia. Digitalization made the tachycardia more troublesome. On omitting it and giving a daily dose of quinidine, no further trouble was experienced. He was still alive two years after his heart attack.

Case 22 (Fig. 1). A man, aged 71, had been known to have had coronary heart disease and intermittent claudication of the legs for the previous four years. He was admitted with an occlusion of an artery of his leg, and showed slight congestive heart failure and an EC. revealed ventricular tachycardia. Digitalization was carried out without any ill effects, 33 grains in four days followed by maintenance dose of $1 \frac{1}{2}$ grains. He was discharged home much improved.

Case 23 (Fig. 12). A woman, aged 46, had undergone X-ray treatment for hyperthyroidism apparently with benefit twenty years previously. Three years ago she again attended the hospital on account of dizziness and giddiness. The heart was thought to be slightly enlarged and an EC. showed the presence of attacks of ventricular tachycardia. Paroxysmal tachycardia was thought to be the cause of her faint spells. She has, therefore, taken a maintenance daily dose of 3 to 6 grains of quinidine with great improvement in her symptoms and lessening of the attacks of tachycardia. She is now well.

Case 24 (Fig. $8 \& 15$ C). A man, aged 30, was first seen by us at the age of 18 years owing to repeated attacks of tachycardia which had been present since childhood. His father, a physician, had observed them at the age of 5 . His only symptom had been a consciousness of almost continuous spells of rapid heart action. Examination did not reveal any obvious abnormality while an EC. showed numerous short runs of ventricular tachycardia. Treatment did not appear to improve his condition.

Case 25 (Fig. 18). A woman, aged 42, began to have attacks of paroxysmal tachycardia eight years ago. They have been and are still frequent and fairly persistent. On examination she has always

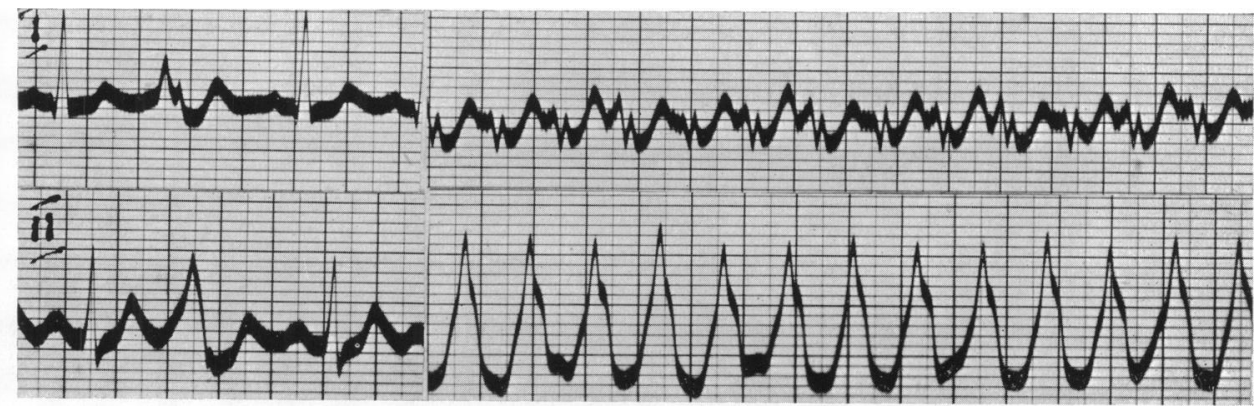

Fig. 18.-Case 25. Leads I and II. Ventricular extrasystoles are shown during normal rhythm. The ventricular complexes during the paroxysms are sufficiently similar to those of the extrasystoles during normal rhythm to indicate the ventricular origin of the tachycardia.

appeared to be perfectly normal. B.P., $130 / 80$; EC. showed that the attacks were ventricular in origin.

Case 26 (Fig. 11). A woman, aged 21, was admitted to the hospital for investigation of her thyroid. She had lost weight and had started to have attacks of rapid heart action six weeks previously. EC., paroxysmal ventricular tachycardia. No organic disease was discovered. Her subsequent history is unknown. 
Case 27 (Fig. 2). A woman, aged 32, had for the past fourteen years had spells of rapid regular racing of the heart, lasting up to 52 hours. The EC. showed a short P-R interval, a widened QRS complex, and runs of ventricular tachycardia. Examination suggested the presence of an interventricular septal defect. She still has frequent attacks of tachycardia but is otherwise well.

\section{Five cases with Paroxysmal Tachycardia of Doubtful Origin}

Case 28 (Fig. 3 A). A man, aged 40, had had attacks of paroxysmal tachycardia for 25 years, almost constant at times. Treatment had little effect. Physical examination showed nothing abnormal.

Case 29 (Fig. 3 B). A man, aged 39, was first seen 16 years ago when he gave a history of having developed pain, dyspnœa, and vomiting after a long quick run. B.P., during the attack, $70 / 55$, and pulse rate 210. Examination was otherwise normal. He is at present well, suffering only an occasional bout of palpitation.

Case 30 (Fig. 3 C). A man, aged 33, was admitted in an attack of tachycardia, paroxysmal in type. Physical examination was negative. Follow-up study ten years later revealed that he had died, but the details and date are unknown.

Case 31 (Fig. 5). A man, aged 25, had developed tachycardia seven years previously while playing a strenuous game of tennis. This attack lasted three days before it was stopped by quinidine. Examination was normal. He has had no more attacks since that time, and is extremely fit and active.

Case 32. (Fig. 3 D). A man, aged 26, was admitted to the hospital following a collapse during a paroxysm of tachycardia. He was also suffering from acute gonococcal urethritis. Physical examination also revealed well-marked mitral and aortic rheumatic heart disease.

\section{REFERENCES}

Adrian, E. D. (1920). J. Physiol., 54, 1.

Adrian, E. D., and Lucas, K. (1912). Ibid., 44, 68.

Albeaux-Fernet, M., and Welti, J. J. (1939). Arch. Mal. Caur., 32, 639.

Ashman, R. (1925), Amer. J. Physiol., 74, 140.

Ashman, R., and Hermann, G. R. (1926). Amer. Heart J., 1, 594.

Barker, P. S., Macleod, A. G., and Alexander, J. (1930). Ibid., 5, 720.

Battro, A. (1937). Las Arrythmias en Clinica, Buenos Aires

Beeson, P. B., and Levine, S. A. (1941). Amer. Heart J., 22, 401.

Bunn, W. H. (1932). Ibid., 8, 714.

Campbell, M., and Elliott, G. A. (1939). Brit. Heart J., 1, 123.

Cushny, A. R. (1897). J. exp. Med., 2, 233.

Danielopolu, D. (1922). Arch. Mal. Coeur., 15, 537.

De Boer, S. (1920-21). J. Physiol., 54, 400.

- (1927). Arch. Mal. Cour., 20, 187.

Drury, A. N., Horsfall, W., and Munly, W. (1922). Heart, 9, 365.

Eccles, J., and Hoff, H. E. (1934). Proc. Roy. Soc. Lond., 115, B, 307.

Elliot, A. R., and Fenn, G. K. (1934). Amer. Heart J., 9, 806.

Erlanger, J., and Gasser, H. S. (1937). Electrical Signs of Nervous Activity, Philadelphia.

Fellerbaum, D. (1923). Amer. J. med. Sci., 166, 211.

Franck, F. (1894). Cliniques Medicale de la charite, Paris.

Froment, R. (1932). Les Tachycardies Paroxystiques Ventriculaires, Paris.

Galavardin, L. (1920). Arch. Mal. Cour., 13, 121.

Garrey, W. E. (1914). Amer. J. Physiol., 33, 397.

- (1924). Physiol. Rev., 14, 215.

Geroudel, E. (1925). Arch. Mal. Caur., 18, 445.

- (1926). Ibid., 18, 639 .

- (1928). Ibid., 21, 273.

Gilchrist, A. B. (1926). Amer. Heart J., 1, 546.

Goldenburg, M., and Rothberger, C. J. (1936). Pflug. Arch. ges. Physiol., 237, 295.

Haberlandt, L. (1918). Z. ges. exper. Med., 68, 257.

Hall, G. E. (1939). Ann. intern. Med., 12, 1.

Hepburn, J., and Rykert, H. E. (1937). Amer. Heart J., 14, 620.

Herring, H.E. (1917). Der Sekundenherztod mit besonderer Berucksochtigung des Herzkammerfimmerns, Berlin.

Hoff, H. E., and Nahum, L. H. (1934). J. Pharm. Exper. Ther., 52, 235.

Hoffman, A. (1900). Die Paroxysmale Tachycardie, Wiesbaden.

Jervell, A. (1934). Acta. Med. Scand., Supp. 59, 626.

Jones, T. D., and White, P. D. (1926). Amer. Heart J., 2, 139.

Kahlstorf, A. (1936). Klin. Wschr., 15, 1028.

Kaufman, R., and Rothberger, C. J. (1917). Z. ges. exper. Med., 5, 349.

Kline, E. M., Conn, J. W., and Rosenbaum, F. F. (1939). Amer. Heart J., 17, 524.

Kobacker, J. L., and Scherf, D. (1929). Z. ges. exper. Med., 67, 372.

Korns, H. M. (1922). Arch. intern. Med., 30, 158.

Levine, S. A. (1927). Amer. Heart J., 3, 177.

Levine, S. A., and Strong, G. F. (1933). Heart, 10, 125.

Levy, R. L. (1921). J. Amer. med. Ass., 76, 1289. 
Levy, R. L. (1922). Arch. intern. Med., 30, 451.

Lewis, T. (1909). Lancet, 1, 382.

- (1909). Heart, 1, 43.

- (1909). Ibid., 1, 262.

(1910). Ibid., 2, 127.

(1911). The Mechanism of the Heart Beat, London.

(1925). Mechanism and Graphic Registration of the Heart Beat, London.

Lewis, T., Feil, H. S., and Stroud, W. D. (1918). Heart, 7, 191.

Lewis, T., and Master, A. M. (1924). Ibid., 11, 371.

Lundy, C. J., and McLellan, L. L. (1934). Ann. intern. Med., 7, 812.

Lundy, C. J., Treiger, J., and Davison, R. (1939). Amer. Heart J., 17, 85.

Luten, D. (1924). Arch. intern. Med., 33, 251. (1925). Ibid., 35, 74.

Luten, D., and Pope, S. (1930). Amer. Heart J., 5, 570.

Mackenzie, J. (1908). Diseases of the Heart, London.

Mackinnon, A. V. (1934). Quart. J. Med., 3, 1.

McMillan, T. M., and Bellet, S. (1931). Amer. Heart J., 7, 70.

Marvin, H. M. (1928). Ibid., 4, 21.

Mayer, A. G. (1908). Carnegie Pub., Washington, 1, 115.

Mines, G. R. (1913). J. Physiol., 46, 349.

Nahum, L. H., and Hoff, H. E. (1938). Amer. J. Physiol., 124, 591. (1939). Amer. Heart J., 17, 585.

Palmer, R. S., and White, P. D. (1928). Ibid., 3, 454.

Prinzmetal, M., and Kellog, F. (1934). Ibid., 9, 370.

Reid, W. D. (1924). Arch. Intern. Med., 33, 23.

Riseman, J. E. F., and Lininthal, H. F. (1941). Amer. Heart J., 22, 219.

Robinson, G. C., and Hermann, G. R. (1921). Heart, 8, 59.

Robinson, G. C., and Wilson, F. N. (1918). J. Pharmacol. exper. Ther., 10, 491.

Rothberger, C. J. (1922). Klin. Wschr., 1, 82. (1931). Ergebn. Physiol., 32, 472.

Scherf, D. (1938). Z. ges. exper. Med., 61, 30.

Scherf, D., and Kisch, F. (1939). Bull. N.Y. Med. College, 2, 73.

Scherf, D., and Schott, A. (1939). Amer. Heart J., 17, 357.

Schlapp (1933). Quart. J. exp. Physiol., 23, 335.

Schwensen, C. (1922). Heart, 9, 199.

Segers, M. (1939). C.R. Soc. Biol., Paris, 130, 1355, 1359; 131, 1294.

Stern, N. S. (1937). Ann. intern. Med., 11, 519.

Strauss, M. B. (1930). Amer. J. med. Sci., 179, 337.

Traube, L. Quoted by Cushny.

Vaughan, W. T. (1918). Arch. intern. Med., 21, 381.

White, P. D., Leach, C. E., and Foote, S. A. (1941). Amer. Heart J., $22,321$.

White, P. D., and Stevens, H. W. (1916). Arch. intern. Med., 18, 712.

Wiggers, C. J. (1937). Physiology in Health \& Disease, London, 2nd ed.

Wolff, L., Parkinson, J., and White, P. D. (1930). Amer. Heart J., 5, 685.

Yater, W. M. (1938). Arch. intern. Med., 62, 1. 